\title{
Agricultural uses of plant biostimulants
}

\author{
Pamela Calvo • Louise Nelson • Joseph W. Kloepper
}

Received: 20 December 2013 / Accepted: 25 April 2014 / Published online: 8 May 2014

(C) The Author(s) 2014. This article is published with open access at Springerlink.com

\begin{abstract}
Background Plant biostimulants are diverse substances and microorganisms used to enhance plant growth. The global market for biostimulants is projected to increase $12 \%$ per year and reach over $\$ 2,200$ million by 2018 . Despite the growing use of biostimulants in agriculture, many in the scientific community consider biostimulants to be lacking peer-reviewed scientific evaluation.

Scope This article describes the emerging definitions of biostimulants and reviews the literature on five categories of biostimulants: i. microbial inoculants, ii. humic acids, iii. fulvic acids, iv. protein hydrolysates and amino acids, and v. seaweed extracts.

Conclusions The large number of publications cited for each category of biostimulants demonstrates that there is growing scientific evidence supporting the use of biostimulants as agricultural inputs on diverse plant species. The cited literature also reveals some commonalities in plant responses to different biostimulants, such as increased root growth, enhanced nutrient uptake, and stress tolerance.
\end{abstract}

Responsible Editor: Philippe Hinsinger.

P. Calvo · J. W. Kloepper $(\triangle)$

Department of Entomology and Plant Pathology, Auburn

University, Auburn, AL 36830, USA

e-mail:kloepjw@auburn.edu

P. Calvo

e-mail: pzc0006@tigermail.com

L. Nelson

Department of Biology, University of British Columbia, Okanagan Kelowna, BC, Canada

e-mail: louise.nelson@ubc.ca
Keywords Microbial inoculants $\cdot$ Humic acid $\cdot$ Fulvic acid · Protein hydrolysates · Amino acids · Seaweed extracts $\cdot$ Biostimulants

\section{Introduction}

Plant biostimulants, or agricultural biostimulants, include diverse substances and microorganisms that enhance plant growth. The global market for biostimulants has been projected to reach $\$ 2,241$ million by 2018 and to have a compound annual growth rate of $12.5 \%$ from 2013 to 2018 (Anonymous, 2013). According to the same study, the largest market for biostimulants in 2012 was Europe. The European biostimulants industry council (EBIC) reported that in 2012 over 6.2 million hectares were treated with biostimulants in Europe (defined as the European Economic Area) (European Biostimulants Industry Council 2013).

The definition and concept of plant biostimulants is still evolving, which is partly a reflection of the diversity of inputs that can be considered to be biostimulants. The breadth of the concept of biostimulants is evident by reviewing two initiatives from consortia of biostimulant industries, one in Europe and one in North America. In Europe, the EBIC defined plant biostimulants as follows. "Plant biostimulants contain substance(s) and/or microorganisms whose function when applied to plants or the rhizosphere is to stimulate natural processes to enhance/ benefit nutrient uptake, nutrient efficiency, tolerance to abiotic stress, and crop quality. Biostimulants have no direct action against pests, and therefore do not fall within the regulatory framework of pesticides" (European Biostimulants Industry 2012a). Hence, this definition differentiates plant biostimulants from biological control and 
from induced resistance against diseases by concentrating on effects related to improved plant growth, stress tolerance and quality. The EBIC later (European Biostimulants Industry 2012b) elaborated on the effects that biostimulants can have on plants as follows. "Biostimulants foster plant growth and development throughout the crop life cycle from seed germination to plant maturity in a number of demonstrated ways, including but not limited to: improving the efficiency of the plant's metabolism to induce yield increases and enhanced crop quality; increasing plant tolerance to and recovery from abiotic stresses; facilitating nutrient assimilation, translocation and use; enhancing quality attributes of produce, including sugar content, colour, fruit seeding, etc.; rendering water use more efficient; enhancing certain physicochemical properties of the soil and fostering the development of complementary soil micro-organisms". Finally, the EBIC concept of biostimulants includes products with some nutrients, provided that the effect on plant growth is not through direct fertilization: "Biostimulants operate through different mechanisms than fertilisers, regardless of the presence of nutrients in the products" (European Biostimulants Industry 2012b).

In North America, the biostimulant coalition defined biostimulants as "substances, including microorganisms, that are applied to plant, seed, soil or other growing media that may enhance the plant's ability to assimilate applied nutrients, or provide benefits to plant development. Biostimulants are not plant nutrients and therefore may not make any nutrient claims or guarantees" (Biostimulant 2013). In a manner similar to the EBIC, the biostimulant coalition followed the definition of biostimulants with a statement of the effects biostimulants have on plants: "They are derived from natural or biological sources and can i) enhance plant growth and development when applied in small quantities; ii) help improve the efficiency of plant nutrients, as measured by either improved nutrient uptake or reduced nutrient losses to the environment, or both; or act as soil amendments to help improve soil structure, function, or performance and thus enhance plant response" (Biostimulant 2013).

The first world congress on the use of biostimulants in agriculture was held in Strasbourg, France in November, 2012 and was attended by over 700 people from 30 countries. The congress aimed to bring together individuals working on aspects of biostimulants in industry, academia, and regulatory agencies. Prior to this congress, the work of evaluating scientific support for claims of biostimulants was advanced by du Jardin (2012) who conducted a bibliographic analysis of plant biostimulants based on eight categories of biostimulants: humic substances, complex organic materials, beneficial chemical elements, inorganic salts (including phosphite), seaweed extracts, chitin and chitosan derivatives, antitranspirants, and free amino acids and other N-containing substances. This analysis listed the major claims for the references found in data bases for each category of biostimulant.

The current review builds on the analysis of du Jardin (2012). The overall aim of the review is to begin a critical review of selected refereed scientific publications, that report effects of the various categories of plant biostimulants arising from the definitions and descriptions of biostimulants that are included in the European and North American biostimulant consortia. Specifically, the categories of plant biostimulants that we review are i. microbial inoculants, ii. humic acids, iii. fulvic acids, iv. protein hydrolysates and amino acids, and v. seaweed extracts.

\section{Microbial inoculants}

The use of microbial inoculants in agriculture has greatly increased during the past two decades (Hayat et al. 2010) as the public and private sector agricultural research and development communities work for solutions to problems associated with modern agriculture. Microbial inoculants are typically classified as biocontrol agents (also called biopesticides) or biofertilizers (Bashan and Holguin 1998). Microbial inoculants that act as biofertilizers are considered as biostimulants in the present review. Biofertilizers are biological products containing living microorganisms that, when applied to seed, plant surfaces, or soil, promote growth by several mechanisms such as increasing the supply of nutrients, increasing root biomass or root area, and increasing nutrient uptake capacity of the plant (Vessey 2003). Biofertilizers can be used as complements to mineral fertilizers (Canbolat et al. 2006). Microbial inoculants mainly include free-living bacteria, fungi, and arbuscular mycorrhizal fungi (AMF) (Berg 2009; Dodd and Ruiz-Lozano 2012; Vessey 2003) that were isolated from a variety of environments including soil, plants, plant residues, water, and composted manures. Among the biofertilizers that have been studied in depth are plant growth-promoting rhizobacteria (PGPR) 
(Kloepper et al. 1989) and plant growth-promoting bacteria (PGPB), both of which are free-living bacteria mainly isolated from the rhizosphere (Bashan et al. 2014). Several reviews of PGPR have been published in the past few years (Antoun and Kloepper 2001; Bhattacharyya and Jha 2012; Spaepen et al. 2009).

During the development of effective microbial inoculants, several factors must be considered. For example, the species and variety of plant can sometimes be a determining factor in obtaining benefits using biofertilizers (Dalmastri et al. 1999; Remans et al. 2008). Different plant species or cultivars can produce different types of root exudates, which support the activity of the inoculated microorganisms and also serve as substrates for the formation of biologically active substances by the microorganisms (Khalid et al. 2004). Reproducibility of effects of microbial inoculants needs to be tested across a range of soil types and environmental conditions. Another key factor for the development of microbial inoculants is the commercial formulation (Bashan et al. 2014). The inoculated microorganisms must survive in the selected formulation and produce the desired activity following inoculation in the field. Also, when used in conventional agriculture, the microorganisms must also be compatible with chemical fertilizers and crop protection chemicals standardly used on seeds or foliage of the target crop.

Plant growth promotion resulting from better nutrient uptake

Enhanced plant growth and yield by microbial inoculants has been linked in some cases to enhanced nutrient uptake and improved nutrient status of the plant. For example, (Wu et al. 2005) reported that plant growth promotion following inoculation of maize (Zea mays) with strains of Bacillus megaterium and Bacillus muciaraglaginous together with AMF was associated with improved nutritional assimilation of plant total $\mathrm{N}$, $\mathrm{P}$, and K. Application of PGPR resulted in a significant increase in $\mathrm{N}, \mathrm{P}$, and $\mathrm{K}$ uptake as well as root and shoot dry weight in cotton (Gossypium hirsutum) (Egamberdiyeva and Höflich 2004) and wheat (Triticum aestivum) (Shaharoona et al. 2008). (Adesemoye et al. 2010) reported that a three-strain mixture of Bacillus spp. PGPR promoted growth of tomato and increased plant uptake of ${ }^{15} \mathrm{~N}$-depleted fertilizer. In a three-year field study with maize, PGPR, $\mathrm{AMF}$ and a combination of the two increased yield and enhanced the total nutrient content of grain per plot (Adesemoye et al. 2008).

Several mechanisms have been reported for how specific microbial inoculants stimulate plant growth and nutrient uptake, including (i) asymbiotic nitrogen fixation (Boddey and Dobereiner 1995; Döbereiner 1997), (ii) solubilization of nutrients (de Freitas et al. 1997), (iii) sequestering of iron by production of siderophores, and (iv) production of volatile organic compounds (VOCs).

Bacteria with the capacity to fix atmospheric nitrogen $\left(\mathrm{N}_{2}\right)$ asymbiotically belong to many different genera, including Azoarcus spp. (Hurek et al., 1994), Beijerinckia spp. (Baldani et al., 1997), Klebsiella pneumoniae (Riggs et al., 2001), Pantoea agglomerans (Riggs et al., 2001), Azotobacter spp. (Mrkovacki and Milic 2001), Azospirillum spp. (Garcia de Salamone et al. 1996), Bacillus polymyxa (Omar et al. 1996), Burkholderia spp. (Baldani et al. 2001), Herbaspirillum spp. (Pimentel et al. 1991), and Gluconoacebacter diazotrophicus (Boddey et al. 2001). Among all these genera, Azospirillum is the most studied (Bashan et al. 2004; Bashan and de-Bashan 2010; Boddey and Dobereiner 1995; Hartmann and Bashan 2009). Azospirillum spp. can be found in close association with plant roots, including inside root tissues. The capacity of Azospirillum spp. to fix atmospheric nitrogen has been widely reported in different crops. (Malik et al. 2002), using ${ }^{15} \mathrm{~N}$ tracer techniques, found that Azospirillum brasilense and Azospirillum lipoferum contributed between $7-12 \%$ of the total nitrogen content of wheat. In contrast, with sugarcane (Saccharum officinarum), 60-80\% of total plant nitrogen came from nitrogen fixation by Azospirillum diazotrophicus (Boddey et al. 1991). Significant increases in nitrogen content by inoculation with Azospirillum spp. have been reported in many crops, including cotton, wheat, sugarcane, and corn (Garcia de Salamone et al. 1996; Fayez and Daw 1987; (Saubidet et al. 2000). It should be noted however that nitrogen fixation does not account for all of the observed growth promotion noted with the use of Azospirillum species.

Some microorganisms increase the availability of selected soil nutrients via enhanced solubilization of the nutrients, thereby allowing plants to take up nutrients in a more efficient way. Low availability of absorbable forms of $\mathrm{P}$ in soil represents an important problem for agricultural systems. Even when $\mathrm{P}$ fertilizers are added to soils, they may not be absorbed by plants 
because $\mathrm{P}$ is readily bound to soil particles, thereby being unavailable for plants (Gyaneshwar et al. 2002). Different bacterial genera have been identified as phosphorus solubilizers (de Freitas et al. 1997), including Pseudomonas spp. (Malboobi et al. 2009; Park et al. 2009), Bacillus spp. (Arkhipova et al. 2005; de Freitas et al. 1997; Sahin et al. 2004; Zaidi et al. 2006), Burkholderia spp. (Tao et al. 2008), Streptomyces spp. (Chang and Yang 2009), Achromobacter spp. (Ma et al. 2009), Microccocus spp. (Dastager et al. 2010), Flavobacterium spp. (Kannapiran and Ramkuma 2011), Erwinia spp. (Rodriguez et al. 2001), and Azospirillum spp. (Rodriguez et al. 2004). The two most reported mechanisms by which microorganisms solubilize $\mathrm{P}$ are production of organic acids (Goldstein 1995) and production of phosphatases (to release organic-P) (Rodriguez et al. 2006). Organic acids transform insoluble phosphate forms to soluble forms through their hydroxyl and carboxyl groups. These groups chelate the cations bound to phosphate, thereby converting it to soluble forms (Kpomblekou and Tabatabai 1994). Organic acids are also responsible for decreasing the $\mathrm{pH}$ of the surrounding soil, thereby releasing phosphate ions (Rodriguez and Fraga 1999). Many different types of organic acids have been linked to phosphate solubilization. The type of organic acid released by a microorganism depends on the species of the microorganism. For example, Bacillus licheniformis and Bacillus amyloliquefaciens species were found to produce mixtures of lactic, isovaleric, isobutyric, and acetic acids. In contrast, gluconic acid seems to be the most frequent organic acid produced by bacteria such as Azospirillum spp. (Rodríguez et al. 2004), Pseudomonas spp., Erwinia herbicola, Pseudomonas cepacia, and Burkholderia cepacia (Rodriguez and Fraga 1999). Organic phosphorus, which is about $30-80 \%$ of soil phosphorus, plays an important role in the phosphorus cycle of agricultural soils (Tarafdar and Gharu 2006). The predominant forms of organic phosphorus are phytates (inositol hexa- and penta-phosphates), which constitute up to $60 \%$ of soil organic phosphorus. However, phytate cannot be taken up by the plant. It must first be dephosphorylated by phosphatases (phytases and phosphatases), (Gyaneshwar et al. 2002; Singh and Satyanarayana 2011). Acid phosphatases and phytases produced by rhizosphere microorganisms are involved in organic- P solubilization. Gram negative bacteria such as Pseudomonas, Burkholderia, Enterobacter, Citrobacter, and Serratia have been reported to produce acid phosphatases (Gügi et al. 1991; Thaller et al. 1995). Organic phosphate in soils is predominantly present as phytate, and production of the enzyme phytase by inoculants including Pseudomonas spp. (Richardson et al. 2009) and Bacillus spp. (Idriss et al. 2002) has been shown to contribute to plant growth promotion. Arbuscular mycorrhizal fungi (AMF) are widespread in the plant kingdom and contribute significantly to plant $\mathrm{P}$ nutrition and growth in natural ecosystems (Smith et al. 2011). AMF colonize most agricultural species and have an important role in the $\mathrm{P}$ nutrition of many farming systems worldwide, especially in soils with low available P (Thompson 1987). The hyphae of AMF colonizing plants have some of the same functions as root hairs with respect to $\mathrm{P}$ acquisition (Jakobsen et al. 2005) and have an especially large influence on $\mathrm{P}$ uptake in varieties with short root hairs (Schweiger et al. 1995).

In addition to $\mathrm{P}$, Potassium $(\mathrm{K})$ is another essential plant nutrient that can be solubilized by soil microorganisms and microbial inoculants. K-solubilizing microorganisms solubilize rock $\mathrm{K}$ minerals, such as micas, illite, and orthoclases, by excreting organic acids that directly dissolve rock $\mathrm{K}$ or chelate silicon ions to solubilize K (Friedrich et al. 1991; Parmar and Sindhu 2013). Application of Bacillus mucilaginosus and $B$. megaterium with rock $\mathrm{K}$ materials resulted in significant increases in available $\mathrm{K}$ in the soil and $\mathrm{K}$ uptake by eggplant roots and shoots (Han and Lee 2005). Sheng and $\mathrm{He}$ (2006) suggested that enhanced K uptake by inoculation with Bacillus edaphicus was due to the production of organic acids (citric, oxalic, tartaric, succinic, and $\alpha$-ketogluconic) that directly dissolve rock $\mathrm{K}$ or chelate silicon ions.

Microbial inoculants have been reported to enhance uptake of other macro and micronutrients, and the mechanisms involved are still being elucidated. Increases in root biomass, root surface area, or root hairs could be indirect mechanisms that enhance the uptake of nutrients. A wide variety of microorganisms such as Pseudomonas spp. and Acinetobacter spp., Azospirillum ssp., Bacillus spp., and AMF have been reported to increase uptake of $\mathrm{Zn}$ (Kohler et al. 2008; Yazdani and Pirdashti 2011), Cu, Mn (Liu et al. 2000), Ca, Mg (Giri and Mukerji 2004; Khan 2005), and S (Banerjee et al. 2006). (Kohler et al. 2008) reported that inoculation with a combination of two different microorganisms, Pseudomonas mendocina and the AMF 
Glomus intraradices, significantly increased uptake of $\mathrm{Fe}, \mathrm{Ca}$, and manganese (Mn) in lettuce (Lactuca sativa).

Bacteria have evolved Fe (III) transport systems that enable them to grow in environments containing very low concentrations of iron. Fe-binding chelators, known as siderophores, bind or capture free Fe (III) and transport iron into the cell (Neilands and Nakamura 1991). Many different types of siderophores have been studied and identified in different bacterial genera including Bacillus (Park et al. 2005; Temirov et al. 2003; Wilson et al. 2006). The relation between siderophore production, plant growth promotion, and uptake of Fe has also been well documented for a variety of plants and microorganisms. Significant increases in tomato and rice growth parameters were reported using a siderophoreproducing strain of Streptomyces (Rungin et al. 2012; Verma et al. 2011). (Sharma et al. 2013) reported that inoculation with a Pseudomonas putida strain increased iron uptake of rice due to siderophore production and increased the iron content in rice grains which enhanced the nutritional value of the rice.

Volatile organic compounds (VOCs) are low molecular-weight compounds, such as alcohols, aldehydes, ketones, and hydrocarbons, that have high enough vapor pressures under normal conditions to vaporize and enter the atmosphere (Ortíz-Castro et al. 2009). VOCs were initially described as contributing to some biocontrol activities of select rhizosphere microorganisms (Fernando et al. 2005; Vespermann et al. 2007). Later, the role of VOCs in plant growth promotion was reported. (Ryu et al. 2003) reported that the VOCs of some PGPR strains contained 2, 3 butanediol and acetoin that were related to growth promotion of Arabidopsis thaliana. In the same way, (Zhuang et al. 2007) found that VOCs produced by one of the same PGPR strains used by (Ryu et al. 2003) regulated genes involved in cell wall modifications and auxin production in A. thaliana.

Plant growth promotion due to increased production of plant hormones resulting from microbial inoculants

The production of plant growth-regulators by many bacterial species and their effect on plant growth was reported more than 30 years ago (Barea et al. 1976). Microbial inoculants, such as PGPR, can alter root architecture and promote plant development via the production or degradation of the major groups of plant hormones (Bhattacharyya and Jha 2012; Dodd et al.
2010; Idris et al. 2007). Microbial inoculants can also modify plant hormone status (Belimov et al. 2009). Phytohormones, like auxins, cytokinins (CKs), gibberellins (GAs), and ethylene (ET), can be synthesized by beneficial microorganisms. These plant hormones regulate multiple physiological processes, including root initiation, root elongation, and root hair formation. They typically operate in complex networks involving cross-talk and feedback (Dodd et al. 2010; Zahir et al. 2003).

Microbial production of the auxin indole-3-acetic acid (IAA) has been extensively reported (Ali et al. 2009). IAA plays a critical role in plant growth and development by influencing many plant functions, including promotion of cell elongation and cell division, apical dominance, root initiation, differentiation of vascular tissue, ethylene biosynthesis, mediation of tropic responses, and the expression of specific plant genes Most studies using microorganisms that produce IAA have reported a link between IAA production and root development and morphology (Aloni et al. 2006; Döbbelaere et al. 1999a). Many different bacterial species can produce IAA through various mechanisms. For example, (Spaepen et al. 2008) found that IAA production by $A$. brasilense was regulated by root exudates. When root exudates decrease and become a limiting factor for bacterial growth, bacterial production of IAA increases, thereby triggering lateral root and root hair formation. A brasilense Sp245, which produces IAA, increased leaf length and shoot dry weight of spring wheat compared to a non-inoculated control (Spaepen et al. 2008). Aeromonas spp., A. brasilense, and Comamonas acidovorans are among the many IAA species that promote plant growth in rice (Oryza sativa) (Mehnaz et al. 2001), wheat (Kaushik et al. 2000), and lettuce (Lactuca sativa) (Barazani and Friedman 1999).

Cytokinins are a broad group of plant growth regulators that share the capacity to induce plant cell division in bioassays. After biosynthesis in root tips and developing seeds, cytokinins are transported to the shoot via the xylem where they regulate several processes, such as cell division, leaf expansion, and senescence (Spaepen et al. 2009). The capacity of microorganisms to produce cytokinins as one mechanism of plant growth promotion was confirmed using bacterial mutants (García de Salamone et al. 2001). Inoculation with Bacillus subtilis caused increased cytokinin content in shoots and roots of lettuce plants and an increase in plant shoot and root weight of approximately $30 \%$ (Arkhipova et al. 2005). 
Application of the cytokinin-producing bacterium $B$. licheniformis resulted in enhanced cell division, higher chlorophyll content, and increased fresh weight and cotyledon size of cucumber (Cucumis sativus) plants (Hussain and Hasnain 2009). The importance of cytokinin-producing bacteria under drought conditions is a topic of renewed interest (Arkhipova et al. 2007).

Gibberellins (GA) are mainly involved in regulating plant cell division and elongation and hence, they influence almost all stages of plant growth, including seed germination, stem and leaf growth, floral induction, and fruit growth (Spaepen et al. 2009). As with auxins and cytokinins, GAs mainly act in combination with other phytohormones. Frankenberger and Arshad (1995) reported that bacteria are able to release GA into the rhizosphere. Several Azospirillum species produce different GAs that are responsible for plant growth promotion that occurs upon inoculation onto plants (Piccoli et al. 1997). Apart from Azospirillum spp., production of gibberellin-like substances has also been claimed in numerous bacterial genera, including Acetobacter diazotrophicus, Herbaspirillum seropedicae (Bastián et al. 1998), and Bacillus spp. (Gutiérrez-Mañero et al. 2001). The exact mechanism of plant growth promotion by GAs remains unclear, although GA-producing PGPR can act by promoting root growth, more particularly by increasing root hair density in root zones involved in nutrient and water uptake, as shown for A. lipoferum inoculation of maize seedlings (Fulchieri et al. 1993). Gibberellin production by Azospirillum spp. and Bacillus spp. has been implicated in the increased ${ }^{15} \mathrm{~N}$ uptake observed after inoculation of wheat roots (Kucey 1988).

The phytohormone ethylene (ET) is well known as a ripening hormone, but it also has a role in other processes, such as seed germination, cell expansion, and leaf and flower senescence. In addition, ET is produced under conditions of both abiotic and biotic stress and is therefore known as the stress hormone (Spaepen et al. 2009). High ET concentrations have an inhibitory effect on root growth, resulting in reduced overall plant growth (Abeles and Wydoski 1987). ET biosynthesis is highly regulated mostly at the key step catalyzed by the enzyme ACC synthase, and hence, regulation of ACC synthase can lead to regulation of ET (Chae and Kieber 2005). Some PGPR express the enzyme L-aminocyclopropane1-carboxylatedeaminase (ACC deaminase), which can degrade ACC to $\alpha$-ketobutyrate and ammonia. A wide range of soil microorganisms, including the fungus
Penicillium citrinum (Honma 1993) produce the enzyme ACC deaminase that degrades ACC to $\alpha$ ketobutyrate and ammonia (Blaha et al. 2006; Chinnadurai et al. 2009). Inoculation of diverse plant species with bacteria expressing ACC deaminase activity stimulates plant growth (Glick et al. 2007; Saleem et al. 2007). (Glick et al. 1998) proposed a model to explain the role of bacterial ACC deaminase in plant growth promotion. As ACC is exuded by plant roots, it is hydrolyzed by bacteria that produce ACC deaminase. ACC concentration outside the roots decreases and more ACC is exuded by the plant. As a result, ACC levels in the plant are lowered and the ET content is reduced (Glick et al. 1998). Once ET is reduced there is an increase in plant biomass (Contesto et al. 2008; Saleem et al. 2007). Bacteria with ACC deaminase activity have been extensively used for alleviating diverse stresses in plants. By reducing the stress hormone ET, these bacteria are able to protect plants from the growth inhibition caused by ET under numerous stress conditions, such as flooding, toxic compounds (both organic compounds and heavy metals), high salt concentrations, drought, and pathogenic attack (Glick et al. 2007; Saleem et al. 2007).

Resistance to drought and salinity stress

Yield losses due to drought and salinity stress are increasing mainly due to climate change and intensive agriculture that leads to soil degradation. It has recently been discovered that some microbial inoculants known to have a positive effect on plant development can also help plants overcome or tolerate abiotic stress conditions, thereby reducing potential yield losses. Increases in soil salinity have become a serious problem for agriculture crops in the last years. Application of some bacteria, such as Rhizobium spp. and Azospirillum spp., increased plant tolerance to salinity conditions (Cordovilla et al. 1999; Hamaoui et al. 2001). Applications of a strain of $A$. lipoferum to wheat plants reduced the negative effect of saline conditions (Bacilio et al. 2004). Drought stress limits growth and production of crop plants, particularly in arid and semiarid areas (Kramer and Boyer 1997). Greenhouse studies revealed that inoculation of maize seedlings with A. brasilense resulted in the mitigation of many negative effects of drought stress (Casanovas et al. 2002). Among the specific effects were increased water content, reduction in the decrease of water potential, increased foliar area 
and total plant biomass, and increased accumulation of proline. Proline is an osmoprotectant that regulates and helps protect the plant from drought stress. In other experiments, inoculation of wheat with $A$. brasilense in non-irrigated soil resulted in a yield increase of $12 \%$. In addition, grains harvested from Azospirilluminoculated plants under drought conditions had increased $\mathrm{Mg}, \mathrm{K}$, and $\mathrm{Ca}$ contents compared to noninoculated plants (Creus et al. 2004). Other bacterial species, such as Pseudomonas spp. and Bacillus spp., have also been reported to stimulate plant growth under dry conditions. Inoculation under drought conditions increased shoot and root biomass and water content (Marulanda et al. 2009). Increased root elongation and root biomass are common in drought-tolerant species (Sharp et al. 2004). Modifications to root development allow better water and nutrient uptake due to greater root exploration of the soil (Padilla and Pugnaire 2007).

With tolerance to drought, bacterial production of hormone-like compounds has been shown to play a key role in ameliorating effects of drought (Döbbelaere et al. 1999). For example, inoculation of white clover (Trifolium repens) with the IAA-producing strains of P. putida and B. megaterium, resulted in increased shoot and root biomass and water content under drought conditions (Marulanda et al. 2009). In addition to IAA, abscisic acid (ABA) is another plant hormone that plays an important role in the whole plant response to drought stress. (Cohen et al. 2008) reported that plants inoculated with the PGPB A. brasilense Sp245 showed more ABA content than non-inoculated plants, and this resulted in enhanced plant drought tolerance. Degradation of the stress hormone ethylene by ACC-deaminase also resulted in greater drought tolerance. Inoculation with Pseudomonas spp. containing ACC-deaminase partially eliminated the effects of drought stress on growth, yield, and ripening of pea (Pisum sativum) (Arshad et al. 2008). One strain of Achromobacter piechaudii ARV8, isolated from an arid desert environment, significantly increased the fresh and dry weights of both tomato and pepper seedlings exposed to water stress. In addition, the bacterium reduced the production of ethylene by tomato seedlings, following water stress (Mayak et al. 2004).

AMF are known to enhance plant establishment and drought tolerance (Querejeta et al. 2003) by various mechanisms including (a) improved water uptake, by which AMF effectively extend plant roots making the uptake of water much more efficient; (b) better mineral nutrition, especially phosphorus, as a consequence of effectively extending roots; (c) alterations in root architecture; (d) modification of some physiological and enzymatic activities, especially those involved in plant antioxidative responses; and (e) induction of the plant hormone ABA, which can play an important role in mediating some plant responses to different stresses including drought (Gamalero et al. 2009). Many plant species, including corn, soybean (Glycine max), wheat, onion (Allium cepa), and lettuce, have shown enhanced drought tolerance as a consequence of mycorrhizal symbioses (Augé 2001; Brundrett 1991a, 1991b). Under these conditions, AMF enhanced root surface area and promoted dense root growth, resulting in improved drought tolerance. Moreover, plants colonized by AMF were able to maintain higher water use efficiency, and growth was increased at a faster rate when irrigation was restored. Such adjustment of osmotic potential is one of the most important factors for plant survival under drought conditions. In addition, AMF may affect plant water potential by modification of soil structure. Hyphae of AMF can increase soil structure by binding soil particles and producing glomalin, an insoluble gluelike substance (Augé 2001). AMF may also play a role in the protection of roots from heavy metal toxicity by mediating interactions between metals and plant roots (Leyval et al. 1997).

Co-inoculation of AMF and PGPR is also a promising strategy to increase plant drought tolerance. It was reported that co-inoculation of the AMF Glomus mosseae and G. intraradices and PGPR Bacillus spp. on lettuce increased plant growth, photosynthetic rate, water use efficiency, and stomatal conductance after drought stress. The effect of the co-inoculation was better than inoculation with only AMF or Bacillus spp. Furthermore, Bacillus spp. inoculation also improved AMF colonization and growth (Vivas et al. 2003).

Fungal-based microbial inoculants have also been reported to induce plant drought tolerance. Previously reported fungi include many genera, such as Neotyphodium spp., Cuvularia spp., Colletotrichum spp., Fusarium spp., Alternaria spp., and Trichoderma spp. which were reported to elicit drought tolerance in tomato (Solanum lycopersicum), pepper (Capsicum annuum), ryegrass, (Lolium perenne) tall fescue (Festuca arundinacea), wheat, and barley (Hordeum vulgare) (Bae et al. 2009; Singh et al. 2011). Interestingly, in addition to exhibiting increased drought tolerance, the inoculated plants expressed a 
range of adaptations to biotic stress and other abiotic stresses including mineral imbalance and salinity (Kim et al. 2012).

Application of microbial inoculants to mitigate salinity stress has been reported. Inoculation with some PGPR, including strains of B. subtilis, Bacillus atrophaeus, Bacillus spharicus, and Staphylococcus kloosii, increased chlorophyll content, nutrient content, and yield of strawberry (Fragaria ananassa) plants growing in high saline soils (Karlidag et al. 2013). In a similar way, under salinity stress inoculation of canola with A. lipoferum resulted in significant increases in shoot and root weights. Azospirillum lipoferum also increased antioxidant levels in the plants. It was postulated that positive effects were due to bacterial production of ACC-deaminase, which reduced ethylene levels caused by the salinity condition (Baniaghil et al. 2013).

AMF have also been shown to increase tolerance to salt stress. Recent reviews have identified numerous physiological mechanisms by which AMF improve plant salinity tolerance (Evelin et al., 2009; Porcel et al. 2012). Improvement in salt tolerance of maize plants inoculated with AMF ( $G$. mosseae) was related to higher accumulation of soluble sugars in the roots, independent of plant nutritional (P) status (Feng et al. 2002). This effect could be responsible for improved plant water status, chlorophyll concentration, and photosynthetic capacity by increasing photochemical efficiency (Sheng et al. 2008). In a manner similar to drought conditions, plant growth under saline stress may be regulated via changes in phytohormone concentrations (Pérez-Alfocea et al. 2010). Hence the capacity of microbial inoculants to induce changes in phytohormones could be one of the mechanisms involved in enhancing plant tolerance to salinity (Dodd and PérezAlfocea 2012; Dodd et al. 2010).

Emerging areas related to microbial inoculants

In recent years, research has shown that microbial inoculants can also play an indirect role on soil remediation and soil fertility. Bioremediation is recognized as an important tool to restore contaminated sites, reforest eroded areas, and restore degraded ecosystems. The plant is the major component of the phytoremediation processes, and application of microbial inoculants in bioremediation of contaminated soil and reforestation of degraded lands is a promising research area (deBashan et al. 2010a; 2010b; 2012; Grandlic et al.
2008; Kuiper et al. 2004; Ma et al. 2011). Application of Kluyvera ascorbata increased several plant parameters and promoted plant growth of tomato, canola (Brassica napus), and Indian mustard (Brassica juncea) grown in soils containing high concentrations of zinc and nickel (Burd et al. 2000). In another study, Pseudomonas spp. increased growth of canola and common reed (Phragmites australis) in the presence of copper or polycyclicaromatic hydrocarbons (Reed and Glick 2005; Reed et al. 2005). The properties of plants used for phytoremediation could be improved by microbial inoculants, but it is important to choose microorganisms that can survive and succeed when used in phytoremediation practices (De-Bashan et al. 2012).

The examples of microbial inoculants discussed above consist of one or a small number of microbial strains which are fermented or grown separately and are then removed from the fermentation medium, concentrated, and then formulated with some carrier into the final product form. An additional category of inoculants consists of mixed culture fermentation to produce a complex microbial mixture together with fermentation metabolites. On example of this category of inoculantbased biostimulants is the product referred to as EM, for "effective microorganisms." As described by Hu and Qi (2013), the inoculant called EM was first described in non-refereed presentations in the early 1900s. The contents of EM were subsequently summarized (Hu and Qi 2013) as containing "about 80 species of microorganisms, which included photosynthetic bacteria, lactic acid bacteria, yeasts, actinomycetes, and fermenting fungi like Aspergillus and Penicillium." The microbes are fermented together in the presence of organic wastes and molasses (Khaliq et al. 2006). Field experiments with cotton showed that EM increased the efficiency of mineral and organic fertilizers, and the combination of EM with organic matter increased yields $23 \%$ compared to treatment with organic matter alone (Khaliq et al. 2006). In contrast, (Mayer et al. 2010) found that EM did not increase yield or soil quality in trials conducted over 4 years in Central Europe. Results of a 13 years trial on wheat in China (Hu and Qi, 2013) found that long-term applications of EM significantly increased yield of wheat, grain nutrition, and biomass of straw. Another example of a biostimulant based on a mixed culture fermentation resulting in microorganisms and their metabolites are variations of the product SoilBuilder. Treatment of plants with SoilBuilder and a different formulation of the same mixed culture 
fermentation product significantly increased weight of squash (Cucurbita pepo) seedlings with 0, 50, and $100 \mathrm{mM}$ added $\mathrm{NaCl}$ (Yildrim 2007). In the same study, treatment with the biostimulants significantly increased weights of transplanted squash plants at the same $\mathrm{NaCl}$ concentrations, and at $50 \mathrm{mM} \mathrm{NaCl}$, there was significantly less $\mathrm{Na}^{+}$in leaves of treated plants. In a study aimed at determining effects of inoculants on emissions of nitrous oxide $\left(\mathrm{N}_{2} \mathrm{O}\right)$ in agriculture, application of SoilBuilder significantly decreased the cumulative emissions of nitrous oxide $\left(\mathrm{N}_{2} \mathrm{O}\right)$ by $80 \%$ in soils fertilized with urea-ammonium nitrate (Calvo et al. 2013). Hence, specific inoculants based on mixed culture fermentation have been shown to have diverse beneficial effects on plants.

Overall, microbial inoculants are gaining more attention due to their potential not only in the agriculture industry but also as tools to solve some environmental problems. In the last years there has been more focus on this potential application as a tool to enhance nutrient uptake in integrated crop management practices. Additional work is needed in order to provide consistent results between laboratory and greenhouse studies and appropriate field applications.

\section{Humic acids}

Humic substances are end products of microbial decomposition and chemical degradation of dead biota in soils (Asli and Neumann 2010, Schiavon et al. 2010) and are considered to be the most abundant naturally occurring organic molecules on earth (Simpson et al. 2002) and the major components of soil organic matter (Nardi et al. 2002). Interestingly, dissolved humic substances are common in freshwater bodies where they have been shown to interact with freshwater organisms, a topic reviewed by (Steinberg et al. 2008). In soil, humic substances are reported to play key roles in various soil and plant functions (Berbara and García 2014) such as controlling nutrient availability, carbon and oxygen exchange between the soil and the atmosphere, and the transformation and transport of toxic chemicals (Piccolo and Spiteller 2003). In addition, humic substances in soils affect plant physiology and the composition and function of rhizosphere microorganisms (Varanini and Pinton 2001).

The activity of humic substances is related to their structural characteristics (Berbara and García 2014).
The general category of humic substances historically includes i) humic acids, which are soluble in basic media and hence are extracted from soil by dilute alkali and precipitate in acidic media, ii) fulvic acids, which are soluble in both alkali and acid media, and iii) humins, which are not extractable from soil (Stevenson 1994, Berbara and García 2014). Another commonly cited difference between humic and fulvic acids is that humic acids are typically high-molecular-weight, while fulvic acids are low-molecular-weight (Nardi et al. 2009). (Nardi et al. 2009) suggested that humin should be described as a humic-containing substance, rather than a humic substance, because it is an aggregate of humic and nonhumic materials (Rice and MacCarthy 1990). The specific structural characteristics of humic acids and fulvic acids vary according to the source organic material and the time of its transformation (Berbara and García 2014).

The understanding of the chemistry of humic substances has advanced considerably during the past two decades. Historically, humic substances were described as refractory, dark-colored heterogeneous organic compounds produced as byproducts of microbial metabolism (Stevenson 1994). The initially produced humic substances can be modified by polymerization, resulting in a diversity of molecular weights ranging from 500 to 1,000,000 D (Piccolo et al. 2002). In a critical review published in 2001, Piccolo (2001) the traditional view that humic substances are present in soils as polymers was challenged. The alternative presented was that humic substances were supramolecular associations of heterogeneous, relatively small molecules. Magnetic resonance tests confirmed that molecular aggregations of mixtures of variously sized humic substances occur in soils (Simpson et al. 2002). Sutton and Sposito (2005) added the understanding that the molecular aggregations of humic substances include micellar structures, which are arrangements of organic molecules in aqueous solutions that form hydrophilic exteriors while containing hydrophobic interiors. The functional significance of this modified structural understanding of humic substances can contain any molecules that are intimately associated with the micellar structure such that they cannot be separated by physical or chemical means (Sutton and Sposito 2005). Kelleher and Simpson (2006) reported that humic substances extracted from soils contained proteins, carbohydrates, aliphatic biopolymers, and lignin, which represent the principal compound classes in plants and microbes. In accordance 
with this theory, previous studies have suggested that humic substances (HS) have only an apparent high molecular size, which can be reversibly disrupted by treating humic solutions with low concentrations of mono, di, and tricarboxylic acids (Nardi et al. 1988; Nardi et al. 1996). More recently, numerous studies have shown that the amphiphilic properties of the organic acids in root exudates can dissociate HS into low molecular size and high molecular size (Nardi et al. 1997, 2000, 2002; Piccolo et al. 2002; Piccolo and Spiteller 2003). This new interpretation support the hypothesis that the conformational behaviour of dissolved humus in the rhizosphere and therefore also the interaction of humic components with plant-root cells, may be controlled by the presence of root-exuded or microbereleased organic acids in the soil solution (Piccolo et al. 2003).

The chemical structure of humic substances affects their function. By the 1980s it was widely accepted that hormone-like activity was exhibited by many fulvic acids and low-molecular-weight humic acids (Albuzio et al. 1989). In a study evaluating five different humic extracts from oxidized coal, a North Dakota Leonardite, and an organic soil, (Piccolo et al. 1992) reported that the smallest molecular size humic fractions showed the most effect on plant uptake of nitrate and hormone-like activity. In addition, the issue of analytical chemistry of humic substances impacts adoption of biostimulants because it is important for the humic products industry (Feller et al. 2010). As recounted by (Lamar et al. 2013), industry representatives and researchers from the International Humic Substances Society (IHSS) met in 2008 to discuss procedures for determining the humic acid and fulvic acid contents of commercial products. The industry representatives later formed the Humic Products Trade Association (HPTA) and agreed on the urgency of developing analytical methods that would detect any adulterants in humic substances products that contained sugars, other carbohydrates, amino acids, or proteinacious materials.

Specific effects of humic acids on plants

\section{Plant growth, yield, and nutrient uptake}

Many humic acids and humic substances have been shown to elicit diverse morphological changes in plants (reviewed by Nardi et al. 2009), leading to changes in plant growth (reviewed by Clapp et al. 2001). In this section, some of the literature published, mainly since 2001, on the benefits of humic acids to plant growth, yield, and nutrition is summarized. Table 1 presents a comprehensive summary of publications, reporting effects of humic substances, both humic acids and fulvic acids, on the growth and physiology of various crops and other plants. Humic acid or humic substances have been reported to enhance some aspect of growth in over 16 species of plants (Table 1) including important agronomic crops such as soybean, wheat, rice, and maize; vegetable crops such as potato, tomato, cucumber, and pepper; fruit crops such as citrus (Citrus limon) and grape (Vitis vinifera); and miscellaneous other crops including Arabidopsis. It is important to note that the majority of the tests have been conducted in growth chamber tests or in hydroponic conditions. Promotion of root system development is the most commonly reported initial effect of humic acids on plant growth. For example, enhancement of lateral roots or general increased seedling root growth has been reported with tomato (Adani et al. 1998; Canellas et al. 2011), Arabidopsis (Dobbss et al. 2010; Canellas et al. 2010), wheat (Tahir et al. 2011; Peng et al. 2001), maize (Canellas et al. 2002 and Canellas et al. 2009; Eyheraguibel et al. 2008; Jindo et al. 2012), pepper (Cimrin et al. 2010), and Lantana camara (Costa et al. 2008). Shoot growth promotion by humic acids has also been reported with cucumber (Mora et al. 2010), tomato (Adani et al. 1998; Lulakis and Petsas 1995), wheat (Tahir et al. 2011), maize (Eyheraguibel et al. 2008), and pepper (Cimrin et al. 2010). In a study with multiple soil applications of humic acid, inhibition of shoot growth of maize was noted in a growth chamber hydroponic study (Asli and Neumann 2010), suggesting that it is possible, at least in experimental conditions, to overapply humic acid.

In addition to increasing overall root growth at early stages of plant development, applications of humic acids have also been reported to increase yield or crop quality in some studies involving full-season growth of plants in greenhouses or field studies (Table 1). In trials with okra (Abelmoschus esculentus) conducted in a wire house in field soil, significant increases in fruits per plant resulted from three rates of humic acid when the recommended fertility was applied but not when the fertility rate was reduced $50 \%$ (Kirn et al. 2010). With grapes, a commercial preparation of humic acids increased the quality of wine grapes by increasing the nitrogen content of grape must which resulted in an enhanced tasting score (Morard et al. 2011). Yield of cucumber was enhanced 


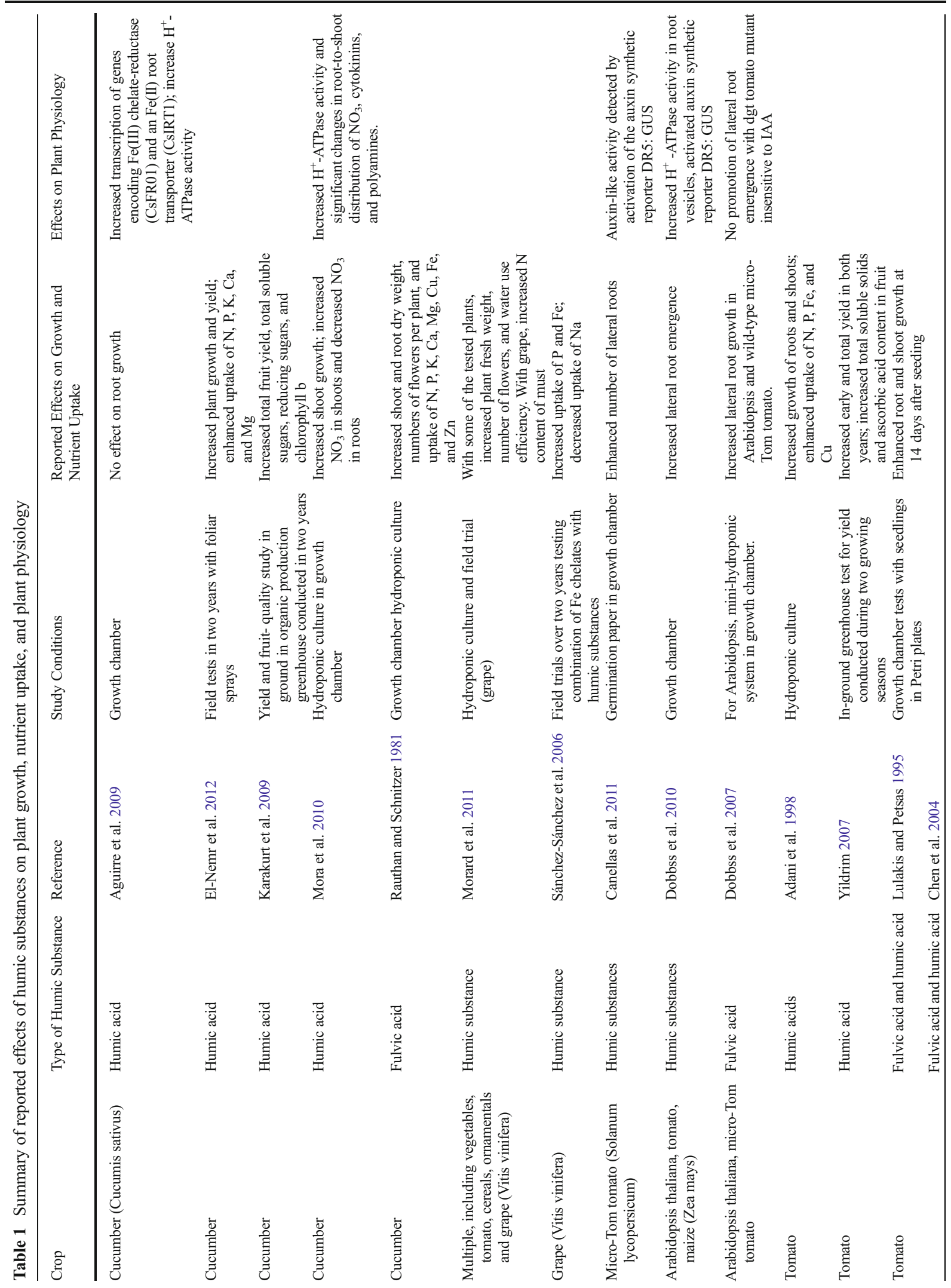




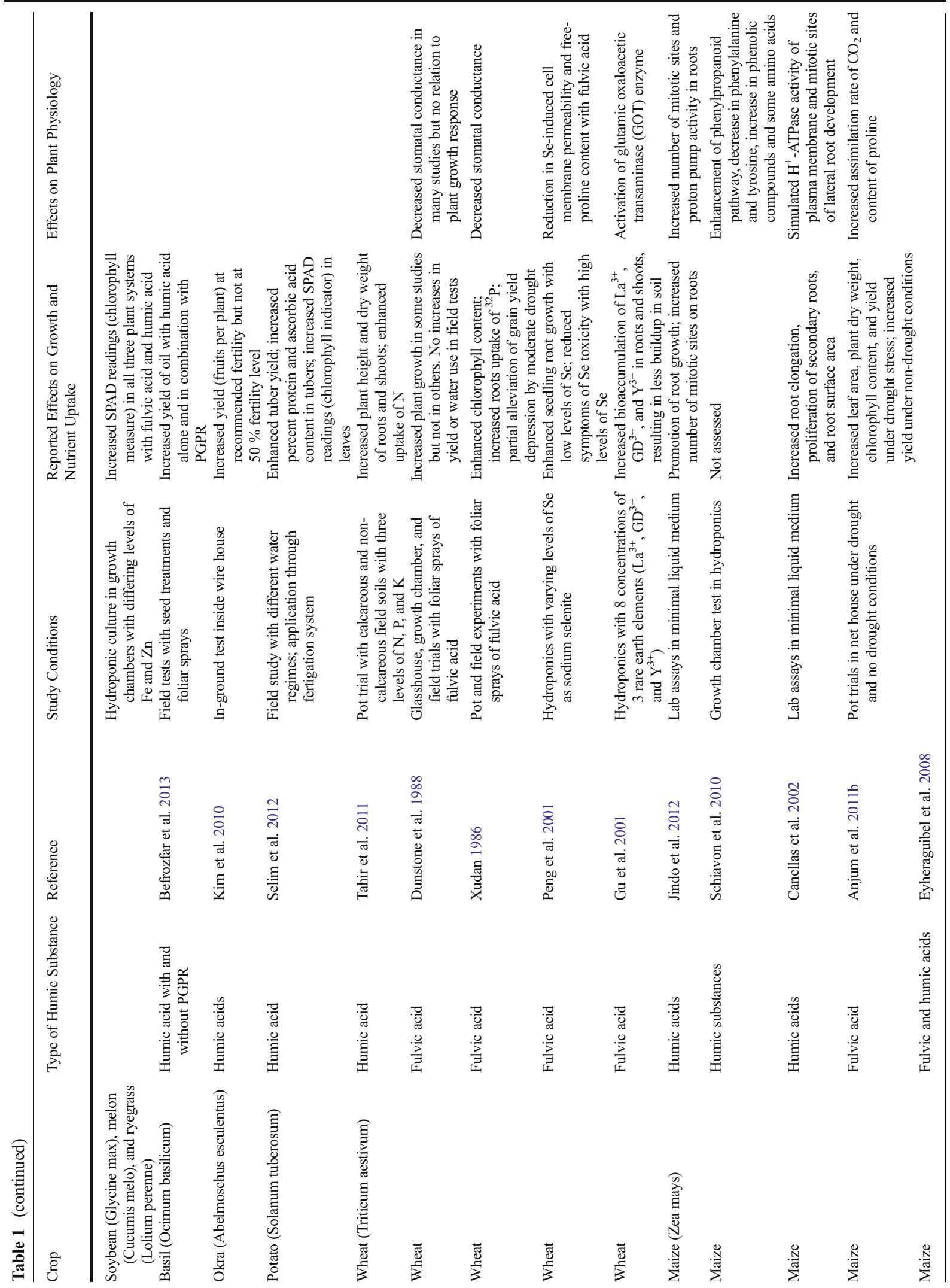




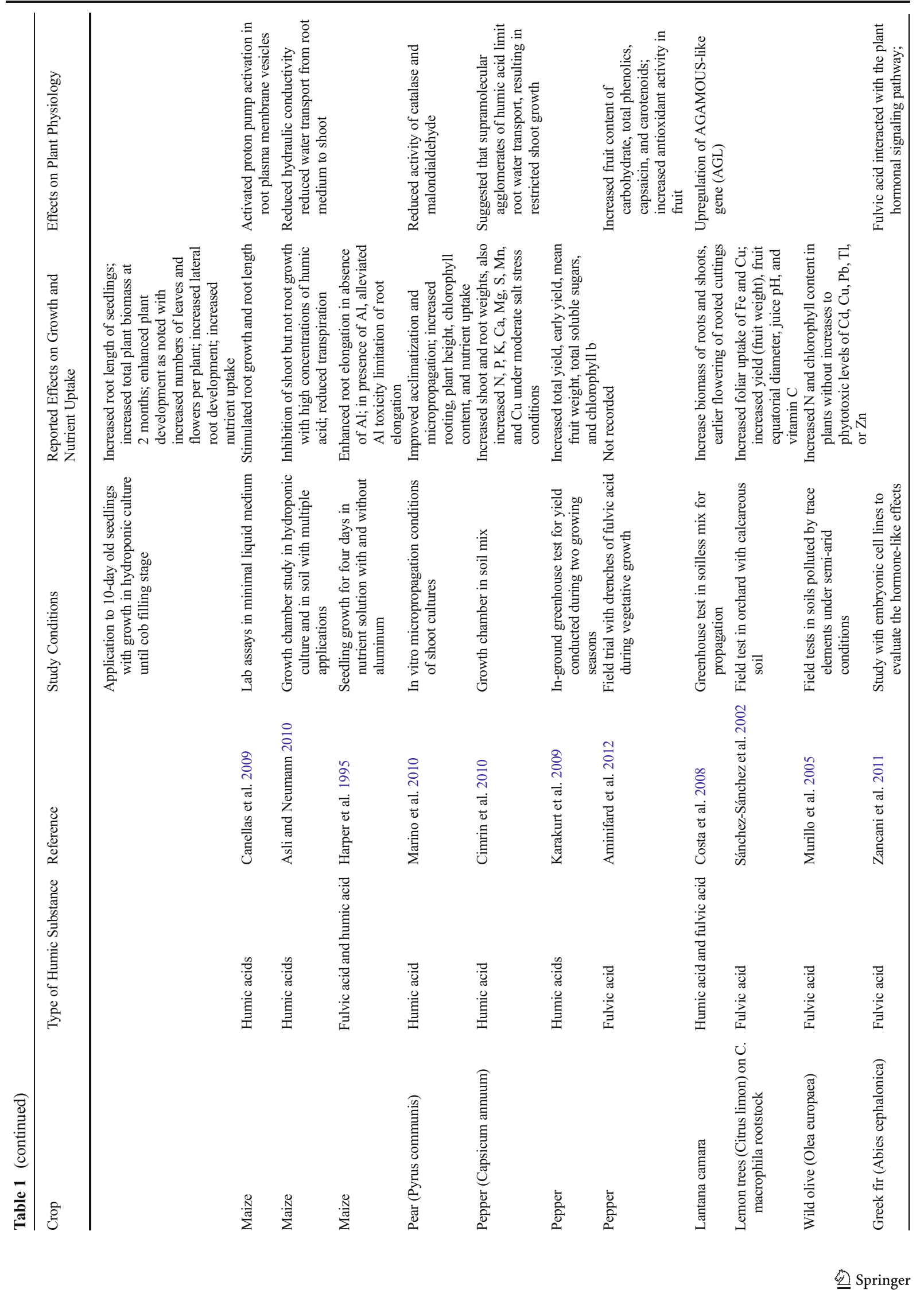




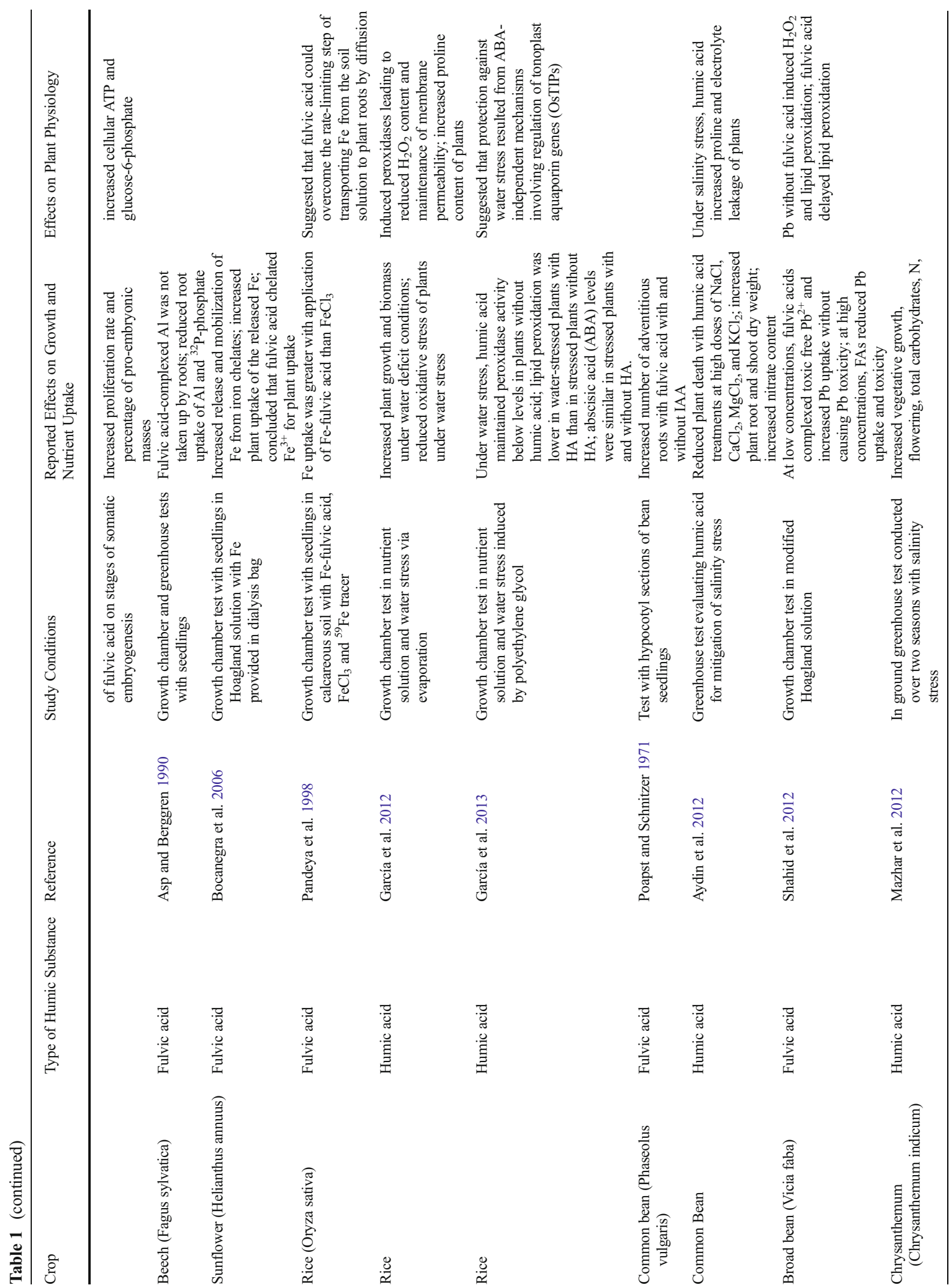




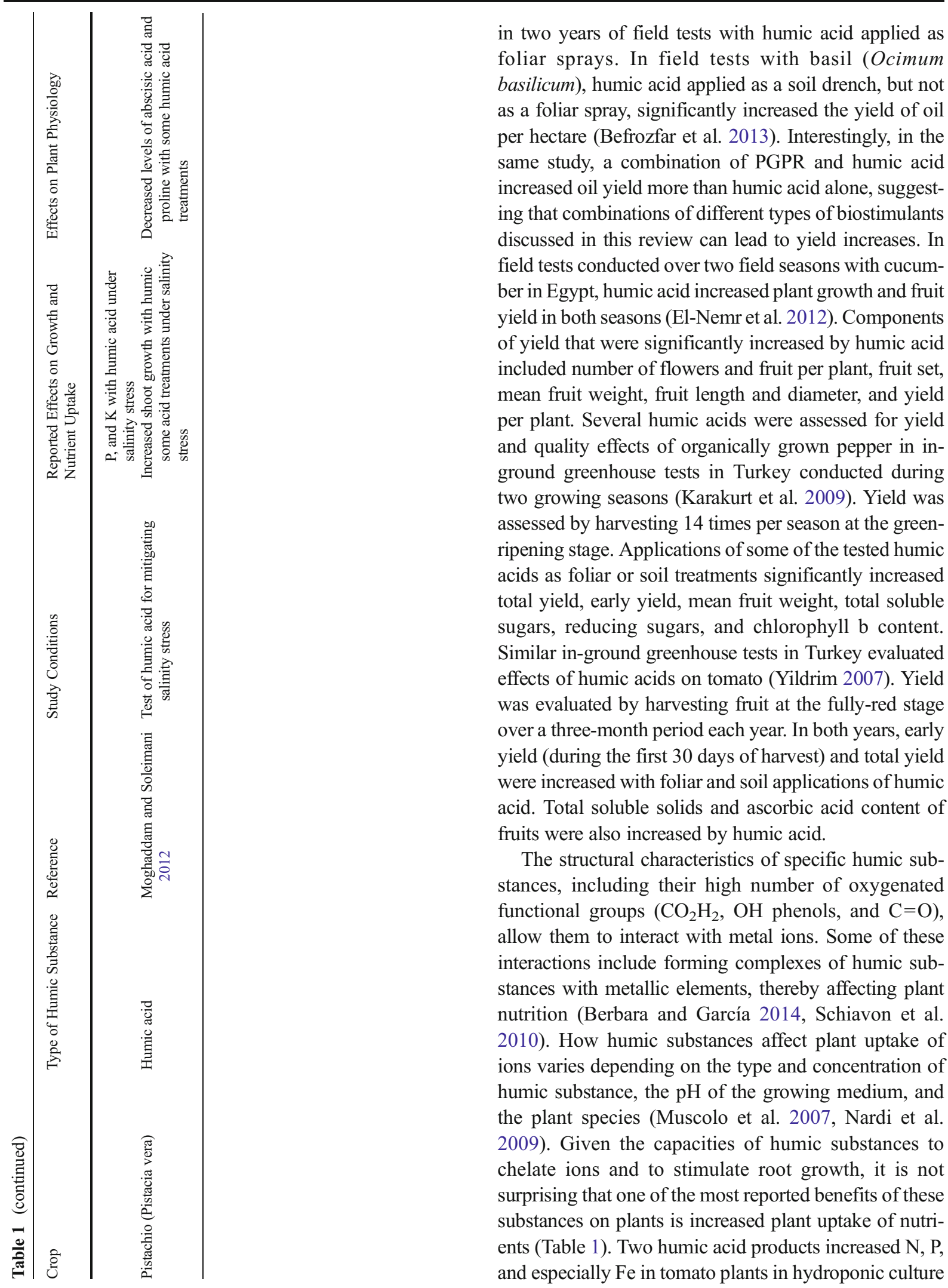


(Adani et al. 1998). Increased uptake of Fe and $\mathrm{P}$ was also reported with the use of a commercial humic acid product on grapes (Sánchez-Sánchez et al. 2006). Increased uptake of $\mathrm{N}, \mathrm{P}, \mathrm{K}, \mathrm{Ca}$, and $\mathrm{Mg}$ was found on pepper (Cimrin et al. 2010), pear (Marino et al. 2010) and cucumber (El-Nemr et al. 2012). Increased nitrate was reported when humic acids were used on bean (Phaseolus vulgaris) (Aydin et al. 2012), wheat (Tahir et al. 2011), and cucumber (Mora et al. 2010). Increased nutrient uptake following application of HS has been linked to increased foliar content of some amino acids, including glutamate, aspartate, serine, glycine, and methionine (Schiavon et al. 2010).

\section{Amelioration of abiotic stress}

The stimulatory effects of humic acids have been shown in some studies to result in enhanced tolerance to salinity stress (Table 1). In studies with bean plants (Aydin et al. 2012), all control plants grown with eight salt sources were killed at the highest dose of $120 \mathrm{mM}$, while no plant dies following treatment with various humic acids at 0.05 and $0.1 \% \mathrm{w} / \mathrm{w}$, with seven of the salt sources including $\mathrm{NaCl}$.. In the same study, treatments with humic acids in saline soils were associated with reduced soil electrical conductivity and reduced leakage of proline from plants, effects which were related to plant tolerance to the saline conditions. Similar results were reported in a study on maize (Mohamed 2012) where humic acids protected against plant death resulting from three forms of calcium salts. Coapplications of humic acids and phosphorus reduced saline stress and increased yields of pepper growing in a moderate salt dose of $8 \mathrm{mM} \mathrm{NaCl}$ (Cimrin et al. 2010), and the $\mathrm{Na}$ concentration in shoots and roots decreased with increasing doses of humic acid. In a greenhouse test on chrysanthemum (Chrysanthemum indicum) grown two seasons in field soils, applications of humic acids ameliorated the negative effects of salinity alone on vegetative growth and flowering (Mazhar et al. 2012). In a field study with pistachio (Pistacia vera), humic acid ameliorated negative effects on plant growth resulting from irrigation with low to moderate rates of $\mathrm{NaCl}$, and this effect was related to a reduction in proline accumulation and decreased levels of abscisic acid (ABA) in plants treated with humic acids compared to controls (Moghaddam and Soleimani 2012).

Investigating the potential of humic acids to aid plants in drought tolerance has begun. Humic acid extracted from vermicompost was evaluated for effects on growth and physiology of rice seedlings grown under water deficient conditions (García et al. 2012). Seedling growth promotion induced by humic acid began at 10 days after germination, which coincided with onset of water stress symptoms. Seedlings treated with humic acid had increased shoot and root dry weights compared to controls under the water-stress conditions. At 25 days after germination under water stress, the levels of chlorophyll, carotenoids, protein, and carbohydrates were greater in treated plants than in controls, indicating that the photosynthetic capacity of water-stressed plants was increased by humic acid. In the same study, effects on plant physiology were evaluated, and these are discussed in the following section.

Plant physiology and metabolism

Humic substances exert beneficial effects on plant physiology by improving soil structure and fertility and by affecting nutrient uptake and root architecture (Trevisan et al. 2010). Fractions of humic acids interact directly with root structures. Studies of humic substances marked with $14 \mathrm{C}$ isotopes have shown that these humic fractions are associated in greater quantities with the cell wall within the first few hours of humic substances-root interaction $(3 \mathrm{~h})$ and subsequently $(18 \mathrm{~h}$ ) become part of the soluble component of the cells (Berbara and García 2014). Most humic substances bind tightly to plant cell walls and can be absorbed by roots where some of them can transfer to the shoots (Nardi et al. 2009). This direct plant uptake allows the humic substances to exert direct effects on plant metabolism (reviewed in Nardi et al. 2009). The specific physiological effects of humic substances on plants depend on the source, the concentration, and the molecular weight of the humic fractions applied (Nardi et al. 2002). (Trevisan et al. 2010) reviewed the signaling events that affect the physiological effects of humic substances on plant metabolism. As described above, humic acids have auxin-like effects on plants, and this primary effect was cited as the main biological factor accounting for the diverse beneficial effects on plants. For example, enhanced lateral root development by humic substances is related to mechanisms of cell division that are under the control of auxin. In a study on maize, (Canellas et al. 2009) showed that humic acids increased ATPase activity in root cells and caused increases in root area, while others increased root density. These results were interpreted as suggesting that 
hydrophobic interactions of humic acids in the rhizosphere may release auxin-like compounds that promote root growth. Support for this suggestion was reported in two independent studies using the auxin-synthesis promoter DR5 fused to a GUS reporter gene in transgenic tomato (Canellas et al. 2011; Dobbss et al. 2010).

The role of $\mathrm{H}^{+}$-ATPase activity, also referred to as proton pump activity, in the beneficial effects of humic substances has been reported in several studies. The main function of the plasma membrane $\mathrm{H}^{+}$-ATPase is to create a driving force for uptake and efflux of metabolites and ions across the membrane by generating an electrochemical gradient. (Jindo et al. 2012) reported that humic acid enhanced root growth of maize seedlings by release of auxin-like compounds that induce $\mathrm{H}^{+}$-ATPase activity in the plasma membrane of root cells, resulting in acidification of the apoplast and leading to loosening of cell walls and elongation of root cells. Increased $\mathrm{H}^{+}$-ATPase activity has been associated with humic acid-induced enhanced root elongation and lateral root formation of maize (Canellas et al. 2002; Zandonadi et al. 2007; Canellas et al. 2009). The functionality of $\mathrm{H}^{+}$ATPase and the proton pump has also been linked to nutrient uptake. Treatment of oat (Avena sativa) seedlings with humic substances enhanced proton extrusion from roots, which related to increased nutrient uptake (Pinton et al. 1997). In another study with maize roots, (Pinton et al. 1999) found enhanced nitrate uptake induced by humic substances was related to enhanced plasma membrane $\mathrm{H}^{+}$ATPase activity. However, increased nitrate uptake by plants following treatment with humic substances can also occur by transcriptional activation of specific genes in roots and shoots. In a study on maize, (Quaggiotti et al. 2004) reported that the expression of two putative maize nitrate transporters and a gene encoding an $\mathrm{H}+-$ ATPase isoform was enhanced by humic substances.

Another area of study for understanding how humic substances affect plant growth and development is the role of reactive oxygen species (ROS), which include ${ }^{1} \mathrm{O}_{2}, \mathrm{O}_{2}{ }^{-}, \mathrm{OH}$, and $\mathrm{H}_{2} \mathrm{O}_{2}$. ROS can regulate plant growth through different pathways than those regulated by auxins. ROS signaling is involved in many plant metabolic processes, including regulation and development of plant growth, responses to biotic and abiotic stresses, and cell death (Suzuki et al. 2012). In a study with Arabidopsis roots, disruption of the transcriptional factor UPB1, which regulates cell proliferation and differentiation, resulted in changes in the balance of ROS and a delay in root differentiation (Tsukagoshi et al. 2010). Berbara and García (2014) demonstrated with histochemical staining that ROS was produced in rice plant roots following application of humic acid. In this study, ROS production, especially production of $\mathrm{H}_{2} \mathrm{O}_{2}$ was dependent on the concentration of humic substances. Following treatment with moderate levels of humic substances, the resulting production of ROS did not cause lipid peroxidation. As a result, growth and lateral root formation were favored. In contrast, treatment with high levels of humic substances elevated levels of ROS, which can lead to lipid peroxidation and negative effects on root growth and development.

Effects of humic substances on plant genes and their metabolites have been further characterized in reports using protemotics, trancriptomics, and microarrays. Proteomic analyses of maize roots following applications of humic substances revealed that a total of 42 proteins were differentially expressed by HS, including proteins related to energy, metabolism, and cellular transport (Carletti et al. 2008). This study concluded that the major pathways in the roots affected by humic substances were sucrose metabolism, malate dehydrogenase, ATPases, and cytoskeletal proteins. Transcriptomic analyses with microarrays of metabolic targets of humic acids were reported on winter oilseed rape (Brassica napus), a crop which has low nitrogen use efficiency (Jannin et al. 2012). In plants treated with a humic acid fraction that elicited significant increases in plant dry weight and chlorophyll content 30 days after treatment, genes that were up- or down-regulated were identified. At 1 day after treatment (DAT) with humic acid, no genes were differentially regulated; at 3 DAT, 720 genes in shoots and 366 in roots were significantly affected; and at 30 DAT, no genes in roots and 102 genes in shoots were affected. All the affected genes were involved in plant metabolic pathways, demonstrating that humic acid treatments can result in many potential changes in plant physiology. A transcriptomic approach based on detection of cDNA-AFLP markers was used to study the regulation of Arabidopsis plant genes in response to treatment with humic substances (Trevisan et al. 2011). In total, 133 genes were found to respond to humic substances, and real-time PCR analyses confirmed transcription of 32 of these genes. In a study with humic substances on the woody ornamental plant Lantana camara, genetic analyses of MADS-box AGAMOUS-like ( $A G L$ ) genes were conducted (Costa et al. 2008). MADS box transcription factors are thought 
to have played an important role in the evolutionary development of angiosperms, and one sublineage of MADS box genes, $A G L$ genes, is known to have a diverse role in flower and fruit development in many plant species (Pan et al. 2010). Application of humic substances to lantana enhanced activity of $A G L$ genes.

Investigations into the effects of humic substances on plant physiology have also been directed to studies of abiotic stress. In a study on rice grown under water stress, (García et al. 2012) reported that humic acids induced peroxidase activity in leaves and roots, which led to reduced hydrogen peroxide content, maintenance of membrane permeability, and increased proline content. Increased proline content was also reported to be associated with humic acid-induced mitigations of salinity stress in bean (Aydin et al. 2012). Proline is an antioxidant amino acid that responds to stress events, functions as an osmolyte in root membrane permeability (Berbara and García 2014), stabilizes proteins, and inhibits lipid peroxidation. Hence, proline can be considered an important indicator of abiotic stress (García et al. 2012). In another study on rice under water-stress conditions, García et al. (2013) reported that humic acid maintained peroxidase activity below levels in plants without humic acid and that lipid peroxidation was lower in water-stressed plants with humic acid than in stressed control plants. However, abscisic acid (ABA) levels were similar in stressed plants with and without humic acid. These results suggested that the protection from water stress resulted from ABA-independent mechanisms. Further, regulation of tonoplast aquaporin genes (OsTIPs) by humic acid was indicated as a possible mechanism.

\section{Fulvic acids}

As discussed above in the section on humic acids, humic substances are divided into different categories that include humic acids, fuvic acids, and humins (Berbara and García 2014). The decision to separate humic acid and fulvic acid into two categories for this review was made because many of the experimental and commercial biostimulants currently being developed or marketed are identified specifically as either humic acids or fulvic acids. Similarly, the scientific literature contains reports that specify humic or fulvic acid as well as reports that refer generically to humic substances. In this section, we examine the scientific literature specifically related to fulvic acids, but the reader is also referred to the previous section on humic acids, which includes reports of studies involving the generic term "humic substances." Historically, humic acids were considered to be larger molecules with molecular weights ranging to a few thousand Daltons, while fulvic acids are typically only a few hundred Daltons (Varanini and Pinton 2001). As stated above, fulvic acid is considered to be the soil organic fraction that is soluble in both alkali and acid (Stevenson 1994). Fulvic acids have greater total acidity, greater numbers of carboxyl groups, and higher adsorption and cation exchange capacities than humic acid (Bocanegra et al. 2006). Fulvic acids are responsible for chelation and mobilization of metal ions, including Fe and Al (Esteves da Silva et al. 1998; Lobartini et al. 1998). Given their small molecular size, fulvic acids can pass through micropores of biological or artificial membrane systems, while humic acids cannot. The combined capacity of fulvic acids both to chelate nutrients such as Fe and move through membranes has suggested the fulvic acids may play similar roles as natural chelators in the mobilization and transport of $\mathrm{Fe}$ and other micronutrients (Bocanegra et al. 2006). It has also been suggested that since they have smaller molecular weights, FAs can remain in soil solution even at high salt concentrations and at a wide range of $\mathrm{pH}$ (Zimmerli et al. 2008; Zhuang et al. 2007; Zhang et al. 2010; Zhang \& Ervin 2008; Zhang \& Ervin 2004; Zhang et al. 2006). Therefore they have long-lasting potential to interact with plant roots (Varanini and Pinton 2001).

Specific effects of fulvic acids on plants

\section{Plant growth, yield, and nutrient uptake}

As shown in Table 1, fulvic acids have been reported to enhance some aspect of growth of a similar range of plant species as humic acids, representing over 16 species of plants (Table 1) including agronomic crops such as soybean, wheat, maize, and rice; vegetable crops such as common bean, broad bean (Vicia faba), tomato, cucumber, and pepper; tree species, including wild olive (Olea europaea), Greek Fir (Abies cephalonica), and beech (Fagus sylvatica); and miscellaneous other plants, including Arabidopsis and the woody ornamental Lantanta camara. Over half of these studies were conducted in growth chambers or in hydroponic conditions, and the other half were either greenhouse or field studies.Among all of these reports, 
the most commonly recorded manifestations of plant growth promotion were measures of root growth. For example, the numbers of root initials on hypocotyl sections of common bean were enhanced 6 days after treatment with fulvic acid (Poapst and Schnitzer 1971). In another study (Dobbss et al. 2007), fulvic acid increased the number and length of lateral roots of Arabidopis and micro-Tom tomato. Significant increases in root elongation of maize were noted in two studies (Lulakis and Petsas 1995; Eyheraguibel et al. 2008). Increases in plant growth above ground have also been noted, including enhanced shoot growth of tomato (Lulakis and Petsas 1995), increased dry weight of shoots of wheat and maize (Anjum et al. 2011b; Eyheraguibel et al. 2008; Dunstone et al. 1988), and more flowers per cucumber plant (Rauthan and Schnitzer 1981).

Assessments of the effects of fulvic acids on yield or fruit quality have been reported in a few tests conducted to maturity under greenhouse or field conditions (Table 1). Foliar sprays of fulvic acid were evaluated in pot experiments and in field trials in northern China for effects on plant growth and yield of wheat under conditions of drought (Xudan 1986). In pot experiments, sprays with fulvic acid at the beginning of a 9day drought cycle reduced stomatal conductance and resulted in higher relative water content, water potential, and chlorophyll content in treated plants at the end of the drought cycle. Application of drought conditions in pot tests reduced yield per pot by $30 \%$, and spraying the plants with fulvic acid before application of drought conditions increased yield to $97 \%$ of the irrigated controls. Following the pot trials, field experiments were conducted to determine yield at 25 sites during a field season where rainfall during the growing season was only $11 \mathrm{~mm}$. Grain yield was reported to be increased with fulvic acid treatment under all conditions. It should be noted that the effects on plants reported in this study (Xudan 1986) are given as percentages of controls without statistical analysis. The extensive tests and the severe drought conditions support the premise that fulvic acid can increase yield and reduce drought stress of wheat, but given the lack of statistical analyses of data, it cannot be stated conclusively that the effects are significant. Two years after publication of the work from China, a study in Australia (Dunstone et al. 1988) was published in which fulvic acids from Chinese and Australian sources were applied to wheat in glasshouse and field trials. A series of greenhouse, growth chamber, and field tests were designed to repeat the results from the tests in China by Xudan (1986). Drought conditions were recreated in the glasshouse, and under these conditions, fulvic acids had no effect on stomatal conductance, transpiration per leaf area, or senescence. In growth chamber tests under well-watered conditions, fulvic acid was effective at reducing stomatal conductance. Fulvic acid was found to significantly increase leaf area and above-ground dry weight of seedlings when applied as a seed treatment in studies conducted in a glasshouse and growth chamber. There were no significant effects of fulvic acid on yield in three field trials. Hence, overall, the results of the study in Australia were not in agreement with the tests in China concerning yield increases with fulvic acid following application as leaf sprays. In a net-house trial on maize, applications of fulvic acid under drought conditions increased yield of maize (Anjum et al. 2011b). A field trial in Iran with pepper was conducted specifically to assess effects of fulvic acid, applied as drenches, on fruit quality, especially antioxidant activity (Aminifard et al. 2012). Although overall yield was not assessed, fulvic acid enhanced multiple parameters of fruit quality, including total soluble solids, antioxidant activity, total phenolics, carbohydrates, capsaicin, and carotenoids. A field study of lemon (Citrus limon) trees in Spain, which was primarily designed to evaluate Fe uptake (SánchezSánchez et al. 2002), also reported effects on fruit yield. Soil applications of a "humic substance" that was shown with analysis to be $90.7 \%$ fulvic acid, resulted in increased fruit weight, fruit equatorial diameter, juice $\mathrm{pH}$, and vitamin $\mathrm{C}$ content.

The capacity of fulvic acid to enhance uptake of nutrients has been reported in diverse systems. Early work by Rauthan and Schnitzer (1981) recorded enhanced uptake of $\mathrm{N}, \mathrm{P}, \mathrm{K}, \mathrm{Ca}, \mathrm{Mg}, \mathrm{Cu}, \mathrm{Fe}$, and $\mathrm{Zn}$ in cucumber plants grown in Hoagland solution. Increased $\mathrm{N}$ content in plants was also reported in a study with wild olive (Olea europaea) (Murillo et al. 2005) and in a study with maize (Eyheraguibel et al. 2008). Fulvic acids were reported to enhance uptake of ${ }^{32} \mathrm{P}$ phosphate in wheat (Xudan 1986) and beech (Asp and Berggren 1990). Several studies focused on the interaction of fulvic acids with Fe. In a model soil system without plants, fulvic acid was reported to complex $\mathrm{Fe}^{3+}$ in soil in a soluble form that could be taken up by plants (Esteves da Silva et al. 1998). A subsequent study on sunflower (Helianthus annuus) in Hoagland solution with ${ }^{59} \mathrm{Fe}$ confirmed that fulvic acid chelated $\mathrm{Fe}^{3+}$ and 
increased iron availability to the plant (Bocanegra et al. 2006). Treatment of rice with fulvic acid in calcareous soils enhanced iron uptake, and the efficiency of FeFulvic acid as a fertilizer was greater than that of $\mathrm{FeCl}_{3}$ (Pandeya et al. 1998). In the field study of lemon trees in Spain discussed in the section on yield effects above, (Sánchez-Sánchez et al. 2002) reported increased foliar uptake of $\mathrm{Fe}$ and $\mathrm{Cu}$ following two applications of a humic substance that was $90.7 \%$ fulvic acid.

\section{Amelioration of abiotic stress}

In comparison to the literature on humic acids, there are fewer reports documenting a role of fulvic acids in the amelioration of environmental stresses. However, plant stresses induced by harmful elements in soil and by drought have been shown to be affected by fulvic acids. Studies on effects of fulvic acids on yield of wheat under drought-stress conditions were discussed above in the section on yield increases. Fulvic acid effects on selenium stress were also reported. Selenium (Se) is harmful to plants and exists in soils in parts of China in high levels, resulting in reduced plant growth (Peng et al. 2001). Treatment of wheat with fulvic acids in soils with low Se concentration promoted root growth, and in soils with high Se content, fulvic acids reduced plant symptoms of stunting, leaf chlorosis, and wilt (Peng et al. 2001). Aluminum ( $\mathrm{Al})$ is another element that reaches levels in soil that restricts plant growth. Asp and Berggren (1990) studied the effects of Al interference on uptake of $\mathrm{Ca}^{2+}$ in beech in the presence and absence of fulvic acids. In the presence of fulvic acids and $\mathrm{Al}$, uptake of $\mathrm{Ca}^{2+}$ was increased, and the fulvic acidcomplexed $\mathrm{Al}$ was not available for uptake by roots. In a similar study with maize, (Harper et al. 1995) reported that $\mathrm{FA}$ reduced the negative effects of $\mathrm{Al}$ on root elongation. In China, FAs have been reported to play a role in reduction of stress from the buildup in soil of three rare earth elements (REEs) $\left(\mathrm{La}^{3+}, \mathrm{Gd}^{3+}\right.$, and $\mathrm{Y}^{3}$ ). (Gu et al. 2001) reported that these REEs are widely used as micronutrients in fertilizers of wheat in China and that the resulting increased soil concentrations pose an environmental problem. Foliar sprays of wheat with FAs increased the bioaccumulation of the REEs which could reduce their buildup in soil. As part of a long-term assessment of fast-growing trees for phytoremediation in Spain, treatments of fulvic acid-rich amendment were applied to wild olive trees growing in eroded soils that had been polluted during a chemical spill related to mining (Murillo et al. 2005). The concentrations of trace elements in leaves of plants treated and not treated with fulvic acids were assessed to determine if fulvic acid would increase uptake of potentially toxic trace elements. The overall results indicated that treatments with fulvic acid stimulated growth and chlorophyll content without excessively enhancing uptake of the trace elements. Effects of fulvic acids on $\mathrm{Pb}$ toxicity of plants was investigated using broad bean in growth chamber tests (Shahid et al. 2012). Results showed that fulvic acids at low concentrations complexed toxic free $\mathrm{Pb}^{2+}$ and increased $\mathrm{Pb}$ uptake without resulting in $\mathrm{Pb}$ toxicity. At high concentrations of fulvic acids, $\mathrm{Pb}$ uptake and toxicity were reduced, presumably due to the high binding constant of fulvic acid for $\mathrm{Pb}$. Effects of fulvic acid on maize under drought conditions were reported in a net-house trial (Anjum et al. 2011b). In this test, drought was applied at the tassel stage which is also when fulvic acid was applied as a foliar spray. Plants treated with fulvic acid under drought conditions exhibited increased plant growth (plant height, leaf area, shoot dry weight) and yield (grain yield, kernel rows per cob, and 100kernel weight).

Plant physiology and metabolism

Several studies have been conducted to help elucidate how fulvic acids affect plant physiology in an effort to explain the observed plant growth enhancement and stress tolerance. The capacity of fulvic acid to enhance development of roots in a mini-hydroponic system with micro-Tom tomatoes was shown to be related to auxin by using the auxin-insensitive mutant $d g t$. This mutant does not respond to exogenous IAA, and it did not respond to treatment with fulvic acid, while the wildtype did (Dobbss et al. 2007). Treatment of maize with fulvic acid increased net photosynthesis, transpiration rate, and the intercellular concentration of $\mathrm{CO}_{2}$, effects that were related to plant growth promotion (Anjum et al. 2011b). In the same study, proline accumulation was enhanced by fulvic acid treatment in both waterstressed and well-watered plants. Enhanced proline following treatments with fulvic acid leading to amelioration of abiotic stress was also noted by (Peng et al. 2001) in the studies on selenium stress discussed above. On soybean and ryegrass, increased concentration of chlorophyll was noted following application of fulvic acid (Chen et al. 2004). Fulvic acid applied to cell cultures of Greek fir interacted with the signaling 
pathway for plant hormones and increased intercellular levels of ATP and glucose-6-phosphate, physiological effects that were related to growth promotion (Zancani et al. 2011).

Concluding remarks for humic acids and fulvic acids

The examples cited above indicate that there is much evidence that humic and fulvic acids can interact with soil nutrients and elicit physiological responses in plants that lead to increased plant growth and in some cases to amelioration of abiotic stresses. The large number of studies demonstrating the specific physiological responses of plants to humic substances lends credence to their use. Berbara and García (2014) stated that the application of humic substances is becoming routine in agriculture. The increasing number of publications showing that humic and fulvic acids deliver economically important benefits to plants through enhanced yield, quality, or stress tolerance supports the potential for humic substances to become routine inputs in some agriculture. However, to reach this goal, more replicated field studies are needed to understand the specific ways that humic substances can add value to crop production systems.

\section{Protein hydrolysates and amino acids}

Plant growth stimulation and enhanced tolerance to biotic and abiotic stresses have been reported following application of a variety of protein-based products. These plant stimulatory effects appear to be distinct from the nutritional effect of an additional nitrogen source (Ertani et al. 2009). Implicit in these studies is the assumption that plants can readily take up amino acids and peptides. Watson and Fowden (1975) and Soldal and Nissen (1978) demonstrated that plant roots could take up radio-labelled amino acids and others have confirmed these studies (reviewed by Miller et al. 2007; Nacry et al. 2013). Foliar uptake of amino acids has also been reported (Furuya and Umemiya 2002; Maini 2006; Stiegler et al. 2013).

Protein-based products can be divided into two major categories: protein hydrolysates consisting of a mixture of peptides and amino acids of animal or plant origin and individual amino acids such as glutamate, glutamine, proline and glycine betaine. Protein hydrolysates are prepared by enzymatic, chemical or thermal hydrolysis of a variety of animal and plant residues, including animal epithelial or connective tissues (Cavani et al. 2006; Ertani et al. 2009, 2013a; Grabowska et al. 2012; Kauffman et al. 2007; Kunicki et al. 2010; Maini 2006; Morales-Payan and Stall 2003), animal collagen and elastine (Cavani et al. 2006), carob germ protein (Parrado et al. 2008), alfalfa residue (Schiavon et al. 2008; Ertani et al. 2009, 2013b), wheat-condensed distiller solubles (García-Martínez et al. 2010), Nicotiana cell wall glycoproteins (Apone et al. 2010), and algal protein (De Lucia and Vecchietti 2012). Several are available as commercial products: e.g. Siapton ${ }^{\mathrm{R}}$ or Aminoplant by Isagro $\mathrm{SpA}$, Italy; ILSATOP products by ILSA Italy and Macro-Sorb Foliar by Bioiberica Corp. Spain.

Protein/peptide and free amino acid contents of the hydrolysates vary in these preparations in the range of $1-85 \%(\mathrm{w} / \mathrm{w})$ and $2-18 \%(\mathrm{w} / \mathrm{w})$, respectively. The major amino acids include alanine, arginine, glycine, proline, glutamate, glutamine, valine and leucine (Parrado et al. 2008; Ertani et al. 2009; GarcíaMartínez et al. 2010). Siapton contains a high proportion of proline and glycine while in carob germ hydrolysate glutamine and arginine predominate (Parrado et al. 2008). Other non-protein components present in these hydrolysates may also contribute to the stimulatory effects on plants. For example, in addition to proteins, peptides and free amino acids, carob germ extract hydrolysate contained fats, carbohydrates, macro and micronutrient elements and at least six phytohormones, while an animal-based product, Siapton had a similar profile of proteins, amino acids, fats and macro and micronutrients, but lacked carbohydrates and phytohormones (Parrado et al. 2008). An alfalfa hydrolysate was high in free amino acids $(1.9 \% \mathrm{w} / \mathrm{w})$ and also contained macro and micronutrient elements and auxin- and gibberellin-like activities based on a bioassay (Schiavon et al. 2008). (Ertani et al. 2013a) reported the presence of triacontanol and IAA, both plant growth regulators, in the same alfalfa hydrolysate product and endogenous IAA in a meat hydrolysate (Ertani et al. 2013b). (Kauffman et al. 2005; 2007), working with Macro-Sorb Foliar, derived from the enzymatic hydrolysis of animal membranes and containing $2 \%(\mathrm{w} / \mathrm{v})$ plant available nitrogen, $21.3 \%(\mathrm{w} / \mathrm{v})$ free amino acids, peptides, nucleotides and fatty acids and $14.8 \%(\mathrm{w} / \mathrm{v})$ unknown organic matter, reported that the lipid soluble fraction of the product produced an auxin-like response in vitro equivalent to $0.07 \%(\mathrm{v} / \mathrm{v})$. 
The second category of protein-based products is that of individual amino acids. These include the twenty structural amino acids involved in the synthesis of proteins as well as non-protein amino acids which are found abundantly in some plant species (Vranova et al. 2011). There is considerable evidence that exogenous application of a number of structural and non-protein amino acids, including glutamate, histidine, proline, and glycine betaine can provide protection from environmental stresses or are active in metabolic signalling (Sharma and Dietz 2006; Forde and Lea 2007; Vranova et al. 2011; Liang et al. 2013). Several non-protein amino acids have also been shown to have roles in plant defense which is outside the scope of this review (see Huang et al. 2011; Vranova et al. 2011).

Specific effects of protein hydrolysates and amino acids on plants

\section{Plant nutrient uptake and yield}

Maini (2006) summarized the early studies with the first commercial protein hydrolysate from animal epithelial tissues, Siapton. It was developed in 1969 in Italy for foliar application and has been used in Europe, Middle and Far East, South and Central America. Positive effects on growth and yield of many crops were reported, but the studies were in internal reports or non-peer reviewed journals, not accessible to the authors. Maini (2006) presented data from Stoyanov (1981) claiming enhanced $\mathrm{N}, \mathrm{P}, \mathrm{K}$ and $\mathrm{Mg}$ contents in the grains of maize grown under Mg-deficient conditions and then treated with Siapton and $\mathrm{Mg}$ compared to that with $\mathrm{Mg}$ alone, but no statistical analysis was provided. Similarly, statistical analysis was also lacking for data presented from an unpublished field trial claiming enhanced yield and reduced nitrate content of spinach grown in the presence of low soil $\mathrm{N}$ fertilization and with Siapton foliar spray, compared to reduced $\mathrm{N}$ fertilization alone.

More recent studies in the literature have shown mixed results with respect to yield enhancement and nutrient uptake with protein hydrolysates. Tomato plants fertilized with Siapton or with a carob germ hydrolysate showed increased plant height and number of flowers per plant compared to the control while only those fertilized with carob germ hydrolysate showed enhanced numbers of fruit per plant after 18 weeks growth in a greenhouse (Parrado et al. 2008). (Koukounararas et al. 2013) reported recently that application of
Amino $16^{\mathrm{R}}$, a protein hydrolysate containing $11.3 \% \mathrm{~L}-$ amino acids, to greenhouse tomatoes under varying fertilization levels increased fruit yield and this was associated with increased fruit number or weight depending on the degree of fertilization. Papaya (Carica papaya) yields were increased by $22 \%$ when plants were sprayed at monthly intervals with Siapton (Morales-Payan and Stall 2003). (Kunicki et al. 2010) and Gajc-Wolska et al. (2012) found no effect of Aminoplant (Siapton) on yield of spinach (Spinacia oleracea) and endive (Chicorium pumilum), respectively, in field trials and (Grabowska et al. 2012) showed an effect on carrot (Daucus carota) yield only for one variety in one year of three years of field trials and soluble sugars and carotenoids increased and nitrate content decreased in Aminoplant-treated carrot roots relative to the control in one year of two field trials. An alfalfa hydrolysate increased leaf growth, foliar sugar content and decreased nitrate content of hydroponically-grown maize plants (Schiavon et al. 2008) and in more recent studies, enhanced short-term growth of hydroponically-grown maize in the absence and presence of salt stress ( $\mathrm{NaCl}$ ) (Ertani et al. 2013b). It also increased $\mathrm{K}^{+}$content of leaves in the absence of $\mathrm{NaCl}$ and in the presence of $\mathrm{NaCl}$, enhanced $\mathrm{Na}^{+}$and decreased $\mathrm{K}^{+}$contents in roots and leaves (Ertani et al. 2013b). Similarly, a meat hydrolysate derived from tanning residues increased short-term growth and micro-element content and decreased nitrate, phosphate and sulfate content of hydroponically grown maize seedlings (Ertani et al. 2013a).

Studies with individual amino acids suggest that they may play a signalling role in regulating nitrogen acquisition by roots. Exogenously applied glutamine, in particular, decreased nitrate and ammonium influx and transporter transcript in barley roots (Fan et al. 2006; Miller et al. 2007).

Plant physiology and metabolism

Protein hydrolysates have been shown to stimulate carbon and nitrogen metabolism and to increase nitrogen assimilation. Maini (2006) summarized the early literature showing enhanced activity of NAD-dependent glutamate dehydrogenase, nitrate reductase and malate dehydrogenase in maize following application of Siapton. These results were expanded upon by (Schiavon et al. 2008) who showed that an alfalfa protein hydrolysate applied to hydroponically-grown maize increased the 
activity of three enzymes in the tricarboxylic acid cycle (malate dehydrogenase, isocitrate dehydrogenase and citrate synthase) and five enzymes involved in $\mathrm{N}$ reduction and assimilation (nitrate reductase, nitrite reductase, glutamine synthetase, glutamate synthase and aspartate aminotransferase). Increased gene expression of the three TCA cycle enzymes, nitrate reductase and asparagine synthetase was confirmed by RT-PCR in the roots following application of alfalfa hydrolysate. (Ertani et al. 2013b) reported similar effects of a meat hydrolysate. These data suggest that protein hydrolysates may promote nitrogen assimilation in plants via coordinated regulation of $\mathrm{C}$ and $\mathrm{N}$ metabolism. (Ertani et al. 2009) compared the effects of hydrolysates from alfalfa (Medicago sativa) and meat flour on maize seedling growth and showed increased activities of glutamine synthase (GS) as well as nitrate reductase in leaves and roots compared to the control. Up-regulation of isoforms GS1 and especially of GS2, which is responsible for assimilation of ammonia produced by nitrate reduction, was observed, consistent with a stimulatory effect of the hydrolysates on nitrogen assimilation.

Exogenous application of glutamate slowed primary root growth and enhanced root branching behind the root tip of Arabidopsis, suggesting a signaling role for glutamate and potentially more precise placement of roots within nutrient-rich patches in soil (Walch-Liu et al. 2006a, 2006b; Forde and Lea 2007).

Stimulation of plant defenses to biotic and abiotic stress

There is considerable evidence that protein hydrolysates and specific amino acids including proline, betaine, their derivatives and precursors can induce plant defense responses and increase plant tolerance to a variety of abiotic stresses, including salinity, drought, temperature and oxidative conditions (Ashraf and Foolad 2007; Chen and Murata 2008; Kauffman et al. 2007; Apone et al. 2010; Ertani et al. 2013a). (Kauffman et al. 2007) showed that application of an animal membrane hydrolysate, Macro-Sorb Foliar to perennial ryegrass prior to exposure to prolonged high air temperature stress increased photochemical efficiency and cell membrane integrity compared to control plants. (Apone et al. 2010) reported that an amino acid/peptide/sugar mixture derived from plant cell walls induced the expression of three stress marker genes and two genes involved in the oxidative stress response in Arabidopsis plants and enhanced the tolerance of cucumber plants to oxidative stress. (Ertani et al. 2013a) showed that an alfalfa hydrolysate applied to maize grown hydroponically under increasing salt stress increased plant biomass, reduced the activity of antioxidant enzymes and the synthesis of phenolics, but increased leaf proline and flavonoid content, phenylalanine ammonia-lyase activity and gene expression relative to salt-stressed controls.

Glycine betaine, the N-methyl-substituted derivative of glycine, and proline act as osmoprotectants or osmolytes, stabilizing proteins, enzymes and membranes from the denaturing effects of high salt concentrations and non-physiological temperatures (reviewed by Ashraf and Foolad 2007; Chen and Murata 2008; 2011; dos Reis et al. 2012; Ahmad et al. 2013). Accumulation of glycine betaine and proline is generally correlated with increased stress tolerance and exogenous application of these compounds has been shown to enhance tolerance to abiotic stresses in a variety of higher plants including maize, barley, soybean, alfalfa and rice (Chen and Murata 2008; dos Reis et al. 2012; Ahmad et al. 2013). In addition to their roles in stabilizing proteins and membranes, glycine betaine and proline have been shown to scavenge reactive oxygen species and induce expression of salt stress responsive genes, and genes involved in transcription factors, membrane trafficking and reactive oxygen species (Kinnersley and Turano 2000; Ashraf and Foolad 2007, Einset et al. 2007; 2008; Anjum et al. 2011a; dos Reis et al. 2012; Liang et al. 2013).

Other amino acids have an effect on tolerance to abiotic stresses. Exogenous application of glutamate and/or ornithine, precursors of proline, can also enhance tolerance to salt stress (Chang et al. 2010; da Rocha et al. 2012). Arginine, which plays an important role in nitrogen storage and transport in plants, has been shown to accumulate under abiotic and biotic stress (Lea et al. 2006). The non-protein amino acids betaaminobutyric acid (BABA) and gamma-aminobutyric acid (GABA) increase plant resistance to abiotic and biotic stresses and are thought to act as endogenous signal molecules (Shelp et al. 1999; Kinnersley and Turano 2000; Bouché and Fromm 2004; Jakab et al. 2005; Zimmerli et al. 2008). (Shang et al. 2011) showed that exogenous application of GABA reduced postharvest chilling injury in peache (Prunus persica) and led to enhanced endogenous accumulation of GABA and proline. L-glutamine inhibited the BABA-induced resistance to heat shock and a bacterial pathogen in Arabidopsis (Wu et al. 2010). 
Decreased plant toxicity to heavy metals

Amino acids and peptides play a role in the tolerance of plants to a range of heavy metals. Proline accumulation is induced in many plants subjected to heavy metal stress and some metal-tolerant plants exhibit high constitutive proline content even in the absence of excess metal ions (reviewed by Sharma and Dietz 2006). Proline may function in osmoregulation, by offsetting the water deficit that can arise with heavy metal exposure; it may chelate metal ions within plant cells and in the xylem sap; it may act as an antioxidant, scavenging free radicals formed as a result of heavy metal uptake; and it may function as a regulator (reviewed by Sharma and Dietz 2006). Nickel-hyperaccumulating plants also exhibit higher histidine concentrations and histidine appears to be involved in transport of $\mathrm{Ni}$ from root to shoot (Krämer et al. 1996; Kerkeb and Krämer 2003). There is evidence that other amino acids, including asparagine, glutamine and cysteine and peptides such as glutathione and the phytochelatins are important in chelation of $\mathrm{Zn}, \mathrm{Ni}, \mathrm{Cu}$, As and Cd (Sharma and Dietz, 2006 Sytar et al. 2013).

\section{Concluding remarks for protein hydrolysates and amino acids}

The application of new analytical and molecular tools and carefully controlled studies are providing further insight into the composition of protein hydrolysates and evidence for their ability to stimulate plant growth and enhance resistance to a variety of abiotic stresses (Schiavon et al. 2008; Ertani et al. 2013a, b; Corte et al. 2014). Studies with individual amino acids found as components of hydrolysate preparations lend further support to these claims and offer insights into their activity as signaling molecules, regulators of $\mathrm{C}$ and $\mathrm{N}$ metabolism, and inducers of plant defense responses to stress (Sharma and Dietz 2006; Forde and Lea 2007; Ahmad et al. 2013; Liang et al. 2013). Further transcriptional and metabolomic analyses of plants treated with protein hydrolysates and amino acids are needed to further our understanding of the mechanisms of action of these biostimulants at the cellular and gene level.

Protein hydrolysates are formed from animal or plant waste material. The ability to recycle these wastes into useful agricultural products to improve plant growth and resilience is of environmental benefit. While some concern has been expressed about the safety of hydrolysates derived from animal wastes, a recent report by (Corte et al. 2014) showed that hydrolysates of animal origin prepared by chemical or enzymatic hydrolysis showed no toxic or genotoxic effects on soil microbiota, yeasts, and plant bioassay systems and were considered safe for use in conventional and organic farming.

\section{Seaweed extracts}

Seaweed has been used for millennia, either directly or following composting as a soil amendment to enhance soil fertility and crop productivity (reviewed by Khan et al. 2009; Craigie 2011). Following the initial development of a process to produce liquid extracts of seaweed in the 1950s (Milton 1952), a variety of commercial seaweed extract products are now available worldwide for use in agriculture and horticulture (Khan et al. 2009; Craigie 2011). These extracts are reported to act as chelators, improving the utilization of mineral nutrients by plants and improving soil structure and aeration, which may stimulate root growth (Milton 1964). Seaweed extracts also act as biostimulants, enhancing seed germination and establishment, improving plant growth, yield, flower set and fruit production, increasing resistance to biotic and abiotic stresses, and improving postharvest shelf life (Mancuso et al. 2006; Norrie and Keathley 2006; Hong et al. 2007a, 2007b; Rayorath et al. 2008; Khan et al. 2009; Craigie 2011; Mattner et al. 2013). The biostimulant effects often have been attributed to the presence of plant growth hormones and related low molecular weight compounds present in the extracts (Stirk and van Staden 1997; Tarakhovskaya et al. 2007), but other research suggests that larger molecules including unique polysaccharides and polyphenols may also be important as biostimulants, as allelochemicals, and for enhancing resistance to stress (Klarzynski et al. 2003; Zhang et al. 2006; Rioux et al. 2007; González et al. 2013).

Most commercial seaweed extracts are made from brown seaweeds, including Ascophyllum nodosum, Fucus, Laminaria, Sargassum, and Turbinaria spp. (Hong et al. 2007a, 2007b; Sharma et al. 2012). Commercial extract manufacturing processes are generally proprietary, but may include the use of water, acids, or alkalis as extractants with or without heating, or the physical disruption of seaweed using low temperature milling or high pressure (Herve and Rouillier 1977; Stirk and van Staden 2006; Craigie 2011). The final 
product is prepared as a liquid or as a dried formulation (Stephenson 1974) and may be combined with plant fertilizers and micronutrients (Milton 1962; Craigie 2011). Extracts are active as biostimulants at low concentrations (diluted at 1:1,000 or more), suggesting that the effects observed are likely distinct from those associated with a direct nutritional function (Crouch and van Staden 1993, Khan et al. 2009). Seaweed extracts are a complex mixture of components that may vary according to the seaweed source, the season of collection, and the extraction process used (Khan et al. 2009; Rioux et al. 2009; Sharma et al. 2012; Shekhar et al. 2012). They contain a wide range of organic and mineral components including unique and complex polysaccharides not present in terrestrial plants such as laminarin, fucoidan and alginates, and plant hormones (Sivasankari et al. 2006; Rioux et al. 2007; Khan et al. 2009). Recently (Sharma et al. 2012) and (Shekhar et al. 2012) reported on the compositional analysis of five brown seaweed species from Northern Ireland. Carbon, nitrogen, lipid, and ash contents varied significantly among species with time of collection and type of extraction, and ranged between 25 and $39 \%, 1$ and $3 \%, 1$ and $4 \%$, and 18 and $48 \%$, respectively. IAA concentrations in acid extracts ranged from 3 to $47 \mathrm{ng} / \mathrm{g}$. There were significant differences in the concentrations of the minerals $\mathrm{Fe}, \mathrm{I}, \mathrm{K}, \mathrm{Mg}$ and $\mathrm{S}$ among the five species (Sharma et al. 2012). Characteristic pyrolysis products of fucoidan, mannitol, laminarin, and alginic acid were identified in all five seaweed species, but amounts varied among species. Further, there were differences in fatty acid profiles (Shekhar et al. 2012). Similar variations in compositional analysis were observed with four commercial formulations and two acidic extracts of A. nodusum (Shekhar et al. 2012).

Specific effects of seaweed extracts on plants

Plant nutrient uptake, growth, and yield

Studies have shown that foliar application of seaweed extract leads to enhanced root development in a variety of species, including maize (Jeannin et al. 1991), tomato (Crouch and van Staden 1992), Arabidopsis (Rayorath et al. 2008), grape (Mancuso et al. 2006; Mugnai et al. 2008), strawberry (Alam et al. 2013), winter rapeseed (Jannin et al. 2013), Norway spruce (Picea abies) (Slávik 2005), and lodgepole pine (Pinus contorta) (MacDonald et al. 2012). Increases in lateral root formation (Vernieri et al. 2005), total root volume (Slávik 2005; Mancuso et al. 2006), and root length (Zodape et al. 2011) have been observed and attributed to the presence of phytohormones such as auxins and cytokinins in seaweed extracts (Khan et al. 2011a, 2011b). Seaweed extract application also stimulated mineral nutrient uptake in plants such as lettuce (Crouch et al. 1990), grape (Mancuso et al. 2006), soybean (Rathore et al. 2009), tomato (Zodape et al. 2011), and winter rapeseed (Jannin et al. 2013) with increased accumulation of both macro- $(\mathrm{N}, \mathrm{P}, \mathrm{K}, \mathrm{Ca}$, $\mathrm{S})$ and micro-nutrients $(\mathrm{Mg}, \mathrm{Zn}, \mathrm{Mn}, \mathrm{Fe})$ reported (Crouch et al. 1990, Mancuso et al. 2006, Rathore et al. 2009; Zodape et al. 2011). Indirect stimulation of root growth may also occur via enhancement of associated soil microorganisms by seaweed extracts. Root colonization and in vitro hyphal growth of AMF were improved in the presence of extracts of brown algae (Kuwada et al. 1999). (Alam et al. 2013) showed that seaweed extract increased microbial diversity and activity in the rhizosphere of strawberry, while (Khan et al. 2012; 2013) reported that seaweed extract stimulated alfalfa growth and root nodulation by improving the attachment of Sinorhizobium meliloti to root hairs. Enhancement of root growth and nutrient and water uptake efficiency may also increase aboveground plant growth and yield as well as resistance to abiotic and biotic stresses (Khan et al. 2009).

There are numerous reports of beneficial effects of seaweed extracts on shoot growth and crop yield (reviewed by Verkleij 1992; Stirk and van Staden 2006; Khan et al. 2009; Craigie 2011). Recent studies have shown enhanced growth and yield in agricultural and horticultural crops such as wheat (Kumar and Sahoo 2011), winter rapeseed (Jannin et al. 2013), apple (Malus domestica) (Basak 2008), strawberry (Alam et al. 2013), tomato (Kumari et al. 2011; Zodape et al. 2011), spinach (Fan et al. 2013), okra (Zodape et al. 2008), olive (Olea europaea) (Chouliaras et al. 2009), broccoli (Mattner et al. 2013), and geranium (Pelargonium spp) (Krajnc et al. 2012). Root and shoot growth of the model plant Arabidopsis was also enhanced by treatment with algal extracts (Rayorath et al. 2008). Leaf chlorophyll content was increased following seaweed extract application in a number of studies (Blunden et al. 1997; Mancuso et al. 2006; Sivasankari et al. 2006; Spinelli et al. 2010; Fan et al. 2013; Jannin et al. 2013). This increase appeared to be associated with a reduction in chlorophyll 
degradation (Blunden et al. 1997) and delay in senescence rather than a net increase in photosynthesis rate (Jannin et al. 2013).

\section{Plant metabolism and physiology}

Seaweed extracts have a multitude of effects on plant metabolism (reviewed by Khan et al. 2009), and recent gene expression analyses have provided further insight into the pathways involved. (Fan et al. 2013) observed increases in total soluble protein content, antioxidant capacity, phenolics, and flavonoid content in spinach treated with brown algal extracts. These effects were correlated with increases in transcript abundance of key enzymes involved in nitrogen metabolism (cytosolic glutamine synthetase), antioxidative capacity (glutathione reductase), and glycine betaine synthesis (betaine aldehyde dehydrogenase and choline monooxygenase). Chalcone isomerase activity, a key enzyme in the biosynthesis of flavanone precursors and phenylpropanoid plant defense compounds, also increased following treatment with seaweed extract (Fan et al. 2013).

(Jannin et al. 2013) used microarray analysis to assess the effects of a brown algal extract on the expression of 31,561 genes in Brassica napus. Sixty percent of these genes were not identified, but, of the remainder, about 1,000 known genes were differentially expressed and grouped into nine clusters representing the major metabolic functions of plants. Of these the most affected by algal extract application were those involved in carbon and photosynthesis, cell metabolism, nitrogen and sulfur metabolism, and responses to stress. Genes involved in carbon fixation, including Rubisco and carbonic anhydrase were upregulated by algal extract, which should lead to enhanced starch synthesis. This hypothesis was supported by the microscopic observation of increased number and size of starch granules following extract treatment. With respect to $\mathrm{N}$ and $\mathrm{S}$ metabolism, genes coding for proteins involved in uptake and assimilation of $\mathrm{N}$ were strongly upregulated, and qPCR analysis showed the induction of nitrate transporters in roots of treated plants. One of the genes coding for nitrate transporters, NRT1.1, has been suggested to also have a role in $\mathrm{N}$ sensing and in auxin transport (Krouk et al. 2010; Castaings et al. 2011), leading to enhanced lateral root growth. This hypothesis was supported by the increase in root dry weight of extract-treated plants observed in this study (Jannin et al. 2013). Similarly, genes encoding proteins involved in S uptake, assimilation, and storage were upregulated, which was correlated with the enhanced sulfate uptake and accumulation observed in shoots and roots of extract-treated plants (Jannin et al. 2013).

It is well established that purified seaweed cell wall polysaccharides and derived oligosaccharides can enhance plant growth (reviewed by González et al. 2013). Oligo-alginates derived from brown seaweeds enhanced nitrogen assimilation and basal metabolism in plants (Khan et al. 2011a; Sarfaraz et al. 2011), and oligocarrageenans derived from red algae enhanced photosynthesis, nitrogen assimilation, basal metabolism, cell division, and protection against viral, fungal, and bacterial infections in tobacco (Nicotiana tabacum) and chickpea (Cicer arietinum) (Bi et al. 2011; Castro et al. 2012; Vera et al. 2012). (González et al. 2013) speculate that oligo-alginates and oligo-carrageenans may interact with plasma membrane receptors that use a co-receptor involved in signal transduction leading to simultaneous activation of plant growth and defense against pathogens as has been observed with brassinosteroid-dependent and microbial-associated molecular patterns (MAMPs)-dependent signaling pathways, which have a common co-receptor (Kemmerling et al. 2011).

\section{Resistance to abiotic stress}

Seaweed extracts have been shown to alleviate a variety of abiotic stresses including drought, salinity, and temperature extremes (Nabati et al. 1994; Zhang and Ervin 2004; Mancuso et al. 2006; Khan et al. 2009; Craigie 2011). Our current understanding of how plants respond to environmental stresses has been informed by recent advances in genomics and transcriptomics. Response is mediated via an intricate network of signals that perceive the stress and set in motion molecular, biochemical, and physiological processes that may be unique to each stress (Hirayama and Shinozaki 2010; Krasensky and Jonak 2012; dos Reis et al. 2012). At the molecular level stress-inducible genes are expressed that code for proteins that directly protect against stress, including osmoprotectants, detoxifying enzymes, and transporters and genes that code for proteins that are regulatory in nature such as transcription factors, protein kinases, and phosphatases. Metabolism may be altered by the synthesis of endogenous regulatory molecules, such as salicylic and abscisic acids, and by compatible solutes, such as proline and glycine-betaine that stabilize 
proteins and cell structures, maintain cell turgor, and scavenge reactive oxygen species. At the cellular level there may be changes in the plant membrane, cell wall architecture, cell cycle, and cell division. (Krasensky and Jonak 2012; dos Reis et al. 2012).

The mode of action of seaweed extracts in enhancing stress tolerance in plants is not well understood, but the presence of bioactive molecules in the extracts, such as betaines (Blunden et al. 1997) and cytokinins (Zhang and Ervin 2004), may play a role. Seaweed extracts also increase the endogenous concentrations of stress-related molecules, such as cytokinins, proline, antioxidants, and antioxidant enzymes in treated plants (Zhang and Ervin 2004; 2008; Zhang et al. 2010; Aziz et al. 2011; LolaLuz et al. 2013; Fan et al. 2013). (Rayirath et al. 2009) showed that extracts of $A$. nodosum and its lipophilic fraction increased tolerance of Arabidopsis to freezing temperatures and that this was associated with protection of membrane integrity, reduced expression of chlorophyllase genes, and increased expression of three cold tolerance genes. (Nair et al. 2012) determined that the lipophilic components (LPC) of the seaweed extract increased proline content in Arabidopsis plants undergoing freezing stress and that this increase was associated with increased expression of proline synthesis genes. In addition, the concentration of total soluble sugars in the cytosol and the proportion of unsaturated fatty acids increased in LPC-treated plants under freezing stress. Using transcriptomic and metabolomic approaches they demonstrated that 1,113 genes were differentially expressed in the LPC-treated Arabidopsis undergoing freezing stress and of these 463 were upregulated, including those associated with stress responses, sugar accumulation, lipid metabolism and response to abscisic acid. In a similar study, (Jithesh et al. 2012) showed that treatment of Arabidopsis undergoing salt stress with $A$. nodosum extracts induced many positive regulators of salt tolerance and down-regulated other genes.

\section{Plant hormones}

Seaweed extracts contain a variety of plant hormones including cytokinins, auxins, abscisic acid, gibberellic acid and salicylic acid determined indirectly by bioassays (reviewed by Khan et al. 2009 and Craigie 2011; Khan et al. 2011b) and directly by methods such as high pressure liquid chromatography (HPLC), gas chromatography-mass spectrometry (GC-MS), and liquid chromatography-mass spectrometry (LC-MS) (Stirk et al. 2003; Gupta et al. 2011). Cytokinins and cytokinin-like compounds are the most widely reported in seaweed extracts, followed by auxins and auxin-like compounds (Stirk et al. 2003; Khan et al. 2009; Craigie 2011), and these have often been speculated to be responsible for the plant growth enhancing effects of the extracts (Khan et al. 2009; Craigie 2011). (Wally et al. 2013) determined the phytohormone concentrations in 12 seaweed extracts from different sources by ultraperformance liquid chromatography-electrospray tandem mass spectrometry (UPLC-ESI-MS/MS) and concluded that the phytohormone levels present in seaweed extracts were insufficient to cause significant effects in plants when applied at the recommended rates. However, using phytohormone biosynthetic and insensitive mutants of Arabidopsis mutants coupled with transcript analysis they showed that "alteration in plant phenotype following seaweed extract application results from a modulation of biosynthesis, quantity, and ratios of the endogenously produced cytokinins, auxins and abscisic acid metabolites, rather than from the exogenous phyohormones present within the extracts themselves" (Wally et al. 2013). They observed increases in concentrations of cytokinins and abscisic acid and their metabolites in leaf tissue and decreases in auxin concentrations following treatment with seaweed extract. They suggest that this stimulation of endogenous cytokinin and abscisic acid biosynthetic pathways and repression of auxin biosynthesis likely explains the increased vegetative plant growth and enhanced resistance to drought and salinity stress observed by others following seaweed extract application. The bioactive compounds within the seaweed extracts that lead to activation of the plant phytohormone biosynthetic pathways remain to be determined.

\section{Concluding remarks for seaweed extracts}

Seaweed extracts, which contain a complex mixture of polysaccharides, micronutrients, and plant growth hormones, have been shown to have a stimulatory effect on plant growth and can enhance plant resistance to abiotic and biotic stresses (Khan et al. 2009; Craigie 2011; González et al. 2013). Their modes of action are not yet well understood, but the application of new analytical and molecular tools is providing new insight into their effects on gene expression, biochemical pathways, and physiological processes (Rayirath 
et al. 2009; Nair et al. 2012; Jannin et al. 2013; Wally et al. 2013). Greater understanding of the modes of action of this renewable resource will be helpful in optimizing its use in the sustainable management of agricultural and horticultural systems (Khan et al. 2009; Quilty and Cattle 2011).

\section{Conclusions}

The examples presented in this review clearly show that many scientific studies have demonstrated the potential of various categories of biostimulants to improve crop production and to ameliorate abiotic stresses such as drought and soil salinity. From the fundamental research perspective, more studies on the transcriptomic and proteomic effects of humic substances will help clarify how specific humic substances elicit plant growth, nutrient uptake, and stress-tolerance responses. Such studies also offer the potential to find markers for beneficial responses, and such markers could be used during product development of biostimulants. An obvious area for future research and development of biostimulants is the combination of some of the various categories presented in this review. For example, combinations of microbial inoculants with seaweed extracts or humic substances could theoretically deliver more reproducible benefits to crop production. We began this review by stating that the global market for biostimulants is projected to reach to reach $\$ 2,241$ million by 2018 and to have a compound annual growth rate of $12.5 \%$ from 2013 to 2018 . Achieving this ambitious application of biostimulants will require ongoing investments in research and partnerships between public and private sector stakeholders.

Open Access This article is distributed under the terms of the Creative Commons Attribution License which permits any use, distribution, and reproduction in any medium, provided the original author(s) and the source are credited.

\section{References}

Abeles FB, Wydoski SG (1987) Inhibitors of ethylene synthesis and action: a comparison of their activities in a lettuce root growth model system. J Am Soc Hortic Sci 112:122-125

Adani F, Genevini P, Zaccheo P, Zocchi G (1998) The effect of commercial humic acid on tomato plant growth and mineral nutrition. J Plant Nutr 21:561-575

Adesemoye AO, Torbert HA, Kloepper JW (2008) Enhanced plant nutrient use efficiency with PGPR and AMF in an integrated nutrient management system. Can J Microbiol 54:876-886

Adesemoye AO, Torbert HA, Kloepper JW (2010) Increased plant uptake of nitrogen from ${ }^{15} \mathrm{~N}$-depleted fertilizer using plant growth-promoting rhizobacteria. Appl Soil Ecol 46:54-58

Aguirre E, Leménager D, Bacaicoa E et al (2009) The root application of a purified leonardite humic acid modifies the transcriptional regulation of the main physiological root responses to Fe deficiency in Fe-sufficient cucumber plants. Plant Physiol Biochem 47:215-223

Ahmad R, Lim CJ, Kwon S-Y (2013) Glycine betaine: a versatile compound with great potential for gene pyramiding to improve crop plant performance against environmental stresses. Plant Biotechnol Rep 7:49-57. doi:10.1007/s11816-0120266-8

Alam MZ, Braun G, Norrie J, Hodges DM (2013) Effect of Ascophyllum extract application on plant growth, fruit yield and soil microbial communities of strawberry. Can J Plant Sci 93:23-36

Albuzio A, Nardi S, Gulli A (1989) Plant growth regulator activity of small molecular size humic pfractions. Sci Total Environ 81(82):671-674

Ali B, Sabri AN, Ljung K, Hasnain S (2009) Auxin production by plant associated bacteria: impact on endogenous IAA content and growth of Triticum aestivum L. Lett. Appl Microbiol 48: 542-547. doi:10.1111/j.1472-765X.2009.02565.X

Aloni R, Aloni E, Langhans M, Ulrich C (2006) Role of cytokinin and auxin in shaping root architecture: regulating vascular differentiation, lateral root initiation, root apical dominance and root gravitropism. Ann Bot 97:883-893

Aminifard MH, Aroiee H, Nemati H, Azizi M, Jaafar HZE (2012) Fulvic acid affects pepper antioxidant activity and fruit quality. Afr J Biotechnol 11:13179-13185

Anjum SA, Farooq M, Wang LC et al (2011a) Gas exchange and chlorophyll synthesis of maize cultivars are enhanced by exogenously-applied glycinebetaine under drought conditions. Plant Soil Environ 57:326-331

Anjum SA, Wang L, Farooq M, Xue L, Ali S (2011b) Fulvic acid application improves the maize performance under wellwatered and drought conditions. J Agron Crop Sci 197: 409-417

Anonymous, 2013. Biostimulants market - By Active Ingredients, Applications, Crop Types \& Geography - Global Trends \& Forecasts to 2018. Marketsandmarkets. http://www. marketsandmarkets.com/Market-Reports/biostimulantmarket-1081.html?gclid=CJfhh9TvorgCFcU5QgodkTMApw

Antoun H, Kloepper J (2001) Plant growth promoting rhizobacteria (PGPR). In: Brenner S, Miller JH (eds) Encyclopedia of genetics. Academic Press, New York, pp 1477-1480

Apone F, Tito A, Carola A et al (2010) A mixture of peptides and sugars derived from plant cell walls increases plant defense responses to stress and attenuates ageingassociated molecular changes in cultured skin cells. J Biotechnol 145:367-376

Arkhipova TN, Prinsen E, Veselov SU et al (2007) Cytokinin producing bacteria enhance plant growth in drying soil. Plant Soil 292:305-315. doi:10.1007/s11104-007-9233-5

Arkhipova TN, Veselov SU, Melentiev AI, Martynenko EV, Kudoyarova GR (2005) Ability of bacterium Bacillus subtilis to produce cytokinins and to influence the growth and 
endogenous hormone content of lettuce plants. Plant Soil 272:201-209. doi:10.1007/s11104-004-5047-x

Arshad M, Shaharoona B, Mahmood T (2008) Inoculation with Pseudomonas spp. containing ACC-deaminase partially eliminates the effects of drought stress on growth, yield, and ripening of pea (Pisum sativum L.). Pedosphere 18: 611-620

Ashraf M, Foolad MR (2007) Roles of glycine betaine and proline in improving plant abiotic stress resistance. Environ Exp Bot 59:206-216

Asli S, Neumann PM (2010) Rhizosphere humic acid interacts with root cell walls to reduce hydraulic conductivity and plant development. Plant Soil 336:313-322

Asp H, Berggren D (1990) Phosphate and calcium uptake in beech (Fagus sylvatica) in the presence of aluminium and natural fulvic acids. Physiol Plant 80:307-314

Augé RM (2001) Water relations, drought and vesiculararbuscular mycorrhizal symbiosis. Mycorrhiza 11:3-42. doi:10.1007/s005720100097

Aydin A, Kant C, Turan M (2012) Humic acid application alleviate salinity stress of bean (Phaseolus vulgaris L.) plants decreasing membrane leakage. Afr J Agric Res 7:1073-1086

Aziz NGA, Mahgoub MH, Siam HS (2011) Growth, flowering and chemical constituents performance of Amaranthus tricolor plants as influenced by seaweed (Ascophyllum nodosum) extract application under salt stress conditions. J Appl Sci Res 7:1472-1484

Bacilio M, Rodriguez H, Moreno M, Hernandez JP, Bashan Y (2004) Mitigation of salt stress in wheat seedlings by a gfp-tagged Azospirillum lipoferum. Biol Fert Soils 40: 188-193

Bae H, Sicher RC, Kim MS et al (2009) The beneficial endophyte Trichoderma hamatum isolate DIS $219 \mathrm{~b}$ promotes growth and delays the onset of the drought response in Theobroma cacao. J Exp Bot 60:3279-3295

Baldani VLD, Baldani JI, Döbereiner J (2001) Inoculation of rice plants with the endophytic diazatrophs Herbaspirillum seropedicae and Burkholderia spp. Biol Fertil Soils 30:485-491

Baldani J, Caruso L, Baldani VLD, Goi SR, Döbereiner J (1997) Recent advances in BNF with non-legume plants. Soil Biol Biochem 29:911-922

Banerjee MR, Yesmin L, Vessey JK (2006) Plant growthpromoting rhizobacteria as biofertilizers and biopesticide. In: Rai MK (ed) Handbook of microbial biofertilizers. Food Products Press, New York, pp 137-181

Baniaghil N, Arzanesh MH, Ghorbanli M, Shahbazi M (2013) The effect of plant growth promoting rhizobacteria on growth parameters, antioxidant enzymes and microelements of canola under salt stress. J Appl Environ Biol Sci 3:17-27

Barazani O, Friedman J (1999) Is IAA the major root growth factor secreted from plant-growth-mediating bacteria? J Chem Ecol 25:2397-2406. doi:10.1023/a:1020890311499

Barea JM, Navarro E, Montoya E (1976) Production of plant growth regulators by rhizosphere phosphate-solubilizing bacteria. J Appl Bacteriol 40:129-134

Basak A (2008) Effect of preharvest reatment with seaweed products, Kelpak ${ }^{\circledR}$ and Goemar BM86 ${ }^{\circledR}$, on fruit quality in apple. Int J Fruit Sci 8:1-14

Bashan Y, De-Bashan LE (2010) How the plant growth-promoting bacterium Azospirillum promotes plant growth - a critical assessment. Adv Agron 108:77-136
Bashan Y, De-Bashan LE, Prabhu SR, Hernandez J-P (2014) Advances in plant growth-promoting bacterial inoculant technology-formulations and practical perspectives (19982013). Plant Soil. doi:10.1007/s11104-013-1956-x

Bashan Y, Holguin G (1998) Proposal for division of plant growthpromoting rhizobacteria into two classifications: biocontrolPGPB (Plant growth-promoting bacteria) and PGPB. Soil Biol Biochem 30:1225-1228

Bashan Y, Holguin G, de Bashan LE (2004) Azospirillum-plant relationship: physiological, molecular, agriculture, and environmental advances (1997-2003). Can J Microb 50: $521-577$

Bastián F, Cohen A, Piccoli P et al (1998) Production of indole-3acetic acid and gibberellins A1 and A3 by Acetobacter diazotrophicus and Herbaspirillum seropedicae in chemically-defined culture media. Plant Growth Regul 24: 7-11

Befrozfar MR, Habibi D, Asgharzadeh A, Sadeghi-Shoae M, Tookallo MR (2013) Vermicompost, plant growth promoting bacteria and humic acid can affect the growth and essence of basil (Ocimumbasilicum L.). Ann Biol Res 4:8-12

Belimov AA, Dodd IC, Hontzeas N et al (2009) Rhizosphere bacteria containing 1-aminocyclopropane-1-carboxylate deaminase increase yield of plants grown in drying soil via both local and systemic hormone signalling. New Phytol 181: 413-423. doi:10.1111/j.1469-8137.2008.02657.x

Berbara RLL, García AC (2014) Humic substances and plant defense metabolism. In: Ahmad P, Wani MR (eds) Physiological mechanisms and adaptation strategies in plants under changing enviornoment: volume 1 . Springer Science+Business Media, New York, pp 297319

Berg G (2009) Plant-microbe interactions promoting plant growth and health: perspectives for controlled use of microorganisms in agriculture. Appl Microbiol Biotechnol 84:11-18. doi:10. 1007/s00253-009-20 92-7

Bhattacharyya PN, Jha DK (2012) Plant growth-promoting rhizobacteria (PGPR): emergence in agriculture. World $\mathrm{J}$ Microbiol Biotechnol 28:1327-1350

Bi F, Iqbal S, Arman M, Ali A, M-u H (2011) Carrageenan as an elicitor of induced secondary metabolites and its effects on various growth characters of chickpea and maize plants. J Saudi Chem Soc 15:269-273

Biostimulant Coalition, 2013. What are biostimulants? http:// www.biostimulantcoalition.org/about/

Blaha D, Prigent-Combaret C, Mirza MS, Moenne-Loccoz Y (2006) Phylogeny of the 1 aminocyclopropane-1-carboxylic acid deaminase-encoding gene acdS in phytobeneficial and pathogenic proteobacteria and relation with strain biogeography. FEMS Microbiol Ecol 56:455-470

Blunden G, Jenkins T, Liu Y-W (1997) Enhanced leaf chlorophyll levels in plants treated with seaweed extract. J Appl Phycol 8: 535-543

Bocanegra MP, Lobartini JC, Orioli GA (2006) Plant uptake of iron chelated by humic acids of different molecular weights. Commun Soil Sci Plant Anal 37:1-2

Boddey RM, Dobereiner J (1995) Nitrogen fixation associated with grasses and cereals: recent progress and perspectives for the future. Fert Res 42:241-250

Boddey RM, Polidoro JC, Resende AS, Alves BJR, Urquiaga S (2001) Use of the ${ }^{15} \mathrm{~N}$ natural abundance technique for the 
quantification of the contribution of $\mathrm{N}_{2}$ fixation to sugar cane and other grasses. Aust J Plant Physiol 28:889-895

Boddey RM, Urquiaga S, Reis V, Döbereiner J (1991) Biological nitrogen fixation associated with sugar cane. Plant Soil 137: $111-117$

Bouché N, Fromm H (2004) GABA in plants: just a metabolite? Trends Plant Sci 9:110-115

Brundrett MC (1991a) Mycorrhizas in natural ecosystems. In: Macfayden A, Begoon M, Fitter AH (eds) Advances in ecological research. Academic Press, London, pp 376-391

Brundrett MC (1991b) Mycorrhizas in natural ecosystems. In: Macfayden A, Begoon M, Fitter AH (eds) Advances in ecological research. Academic Press, London, pp 171-314

Burd GI, Dixon DG, Glick BR (2000) Plant growth-promoting bacteria that decrease heavy metal toxicity in plants. Can J Microbiol 46:237-245

Calvo P, Watts DB, Ames RN, Kloepper JW, Torbert HA (2013) Microbial-based inoculants impact nitrous oxide emissions from an incubated soil medium containing urea fertilizers. J Environ Qual 42:704-712. doi:10.2134/ jeq2012.0300

Canbolat M, Bilen S, Çakmakçı R, Şahin F, Aydın A (2006) Effect of plant growth-promoting bacteria and soil compaction on barley seedling growth, nutrient uptake, soil properties and rhizosphere microflora. Biol Fertil Soils 42:350-357. doi:10. 1007/s00374-005-0034-9

Canellas LP, Dantas DJ, Aguiar NO et al (2011) Probing the hormonal activity of fractionated molecular humic omponents in tomato auxin mutants. Ann Appl Biol 159:202-211

Canellas LP, Olivares FL, Okorokaova-Façanha AL, Façanha AR (2002) Humic acids isolated from earthworm compost enhance root elongation, lateral root emergence, and plasma membrane $\mathrm{H}^{+}$-ATPase activity in maize roots. Plant Physiol 130:1951-1957

Canellas LP, Piccolo A, Dobbss LB et al (2010) Chemical composition and bioactivity properties of size-fractions separated from a vermicompost humic acid. Chemosphere 78: 457-466

Canellas LP, Spaccini R, Piccolo A et al (2009) Relationships between chemical characteristics and root growth promotion of humic acids isolated from Brazilian oxisols. Soil Sci 174: 611-620

Carletti P, Masi A, Spolaore B et al (2008) Protein expression changes in maize roots in response to humic substances. $\mathrm{J}$ Chem Ecol 34:804-818

Casanovas EM, Barassi CA, Sueldo RJ (2002) Azospirillum inoculation mitigates water stress effects in maize seedlings. Cerea Res Commun 30:343-350

Castaings L, Marchive C, Meyer C, Krapp A (2011) Nitrogen signalling in Arabidopsis: how to obtain insights into a complex signalling network. J Exp Bot 62:1391-1397

Castro J, Vera J, González A, Moenne A (2012) OligoCarrageenans stimulate growth by enhancing photosynthesis, basal metabolism, and cell cycle in tobacco plants (var. Burley). J Plant Growth Regul 31:173-185

Cavani L, Halle AT, Richard C, Ciavatta C (2006) Photosensitizing properties of protein hydrolysate-based fertilizers. J Agric Food Chem 54:9160-9167

Chae HS, Kieber JJ (2005) Eto Brute? Role of ACS turnover in regulating ethylene biosynthesis. Trends Plant Sci 10:291296. doi:10.1016/j.tplants2005.04.006
Chang C, Wang B, Shi L et al (2010) Alleviation of salt stressinduced inhibition of seed germination in cucumber (Cucumis sativus L.) by ethylene and glutamate. J Plant Physiol 167:1152-1156

Chang CH, Yang SS (2009) Thermo-tolerant phosphatesolubilizing microbes for multi-functional biofertilizer preparation. Bioresour Technol 100:1648-1658

Chen THH, Murata N (2008) Glycinebetaine: an effective protectant against abiotic stress in plants. Trends Plant Sci 13:499-505

Chen THH, Murata N (2011) Glycinebetaine protects plants against abiotic stress: mechanisms and biotechnological applications. Plant Cell Environ 34:1-20

Chen Y, Clapp CE, Magen H (2004) Mechanisms of plant growth stimulation by humic substances: the role of organo-iron complexes. Soil Sci Plant Nutr 50:1089-1095

Chinnadurai C, Balachandar D, Sundaram SP (2009) Characterization of 1- aminocyclopropane-1-carboxylate deaminase producing methylobacteria from phyllosphere of rice and their role in ethylene regulation. World J Microbiol Biotechnol 25:1403-1411

Chouliaras V, Tasioula M, Chatzissavvidis C, Therios I, Tsabolatidou E (2009) The effects of a seaweed extract in addition to nitrogen and boron fertilization on productivity, fruit maturation, leaf nutritional status and oil quality of the olive (Olea europaea L.) cultivar Koroneiki. J Sci Food Agric 89:984-988

Cimrin KM, Önder T, Turan M, Burcu T (2010) Phosphorus and humic acid application alleviate salinity stress of pepper seedling. Afr J Biotechnol 9:5845-5851

Clapp CE, Chen Y, Hayes MHB, Cheng HH (2001) Plant growth promoting activity of humic substances. In: Swift RS, Sparks KM (eds) Understanding and managing organic matter in soils, sediments, and waters. International Humic Science Society, Madison, pp 243-255

Cohen A, Bottini R, Piccoli P (2008) Azospirillum brasilense Sp 245 produces $\mathrm{ABA}$ in chemically-defined culture medium and increases ABA content in arabidopsis plants. Plant Growth Regul 54:97-103. doi:10.1007/s10725-007-9232-9

Contesto C, Desbrosses G, Lefoulon C, Bena G, Borel F, Galland M, Gamet L, Varoquaux F, Touraine B (2008) Effects of rhizobacterial ACC deaminase activity on Arabidopsis indicate that ethylene mediates local root responses to plant growth-promoting rhizobacteria. Plant Scienc 175:178-1

Cordovilla MP, Berrido SI, Ligero F, Lluch C (1999) Rhizobium strain effects on the growth and nitrogen assimilation in Pisum sativum and Vicia faba plant growth under salt stress. J Plant Physiol 154:127-131

Corte L, Dell'Abate MT, Magini A et al (2014) Assessment of safety and efficiency of nitrogen organic fertilizers from animal-based protein hydrolysates - a laboratory multidisciplinary approach. J Sci Food Agric 94:235-245

Costa G, Labrousse P, Bodin C et al (2008) Effects of humic substances on the rooting and development of woody plant cuttings. Acta Hortic 779:255-261

Craigie JS (2011) Seaweed extract stimuli in plant science and agriculture. J Appl Phycol 23:371-393

Creus CM, Sueldo RJ, Barassi CA (2004) Water relations and yield in Azospirillum-inoculated wheat exposed to drought in the field. Can J Bot 82:273-281

Crouch IJ, Beckett RP, van Staden J (1990) Effect of seaweed concentrate on the growth and mineral nutrition of nutrientstressed lettuce. J Appl Phycol 2:269-272 
Crouch IJ, van Staden J (1992) Effect of seaweed cocentrate on the establishment and yield of greenhouse tomato plants. J Appl Phycol 4:291-296

Crouch IJ, van Staden J (1993) Evidence for the presence of plant growth regulators in commercial seaweed products. Plant Growth Regul 13:21-29

da Rocha IMA, Vitorello VA, Silva JS et al (2012) Exogenous ornithine is an effective precursor and the $\delta$-ornithine amino transferase pathway contributes to proline accumulation under high $\mathrm{N}$ recycling in salt-stressed cashew leaves. J Plant Physiol 169:41-49

Dalmastri C, Chiarini L, Cantale C, Bevinino A, Tabacchioni S (1999) Soil type and maize cultivar affect the genetic diversity of maize root-associated Burkholderia cepacia populations. Microb Ecol 38:273-284

Dastager SG, Deepa CK, Pandey A (2010) Isolation and characterization of novel plant growth promoting Micrococcus sp NII-0909 and its interaction with cowpea. Plant Physiol Biochem 48:987-992. doi:10.1016/j.plaphy. 2010.09.006

De-Bashan LE, Hernandez J-P, Bashan Y, Maier RM (2010a) B. pumilus ES4: Candidate plant growth-promoting bacterium to enhance establishment of plants in mine tailings. Environ Exp Bot 69:343-352

De-Bashan LE, Hernandez J-P, Nelson KN, Bashan Y, Maier RM (2010b) Growth of quailbush in acidic, metalliferous desert mine tailings: Effect of $A$. brasilense Sp6 on biomass production and rhizosphere community structure. Microb Ecol 60:915-927

De-Bashan LE, Hernandez J-P, Bashan Y (2012) The potential contribution of plant growth-promoting bacteria to reduce environmental degradation - A comprehensive evaluation. Appl Soil Ecol 61:71-189. doi:10.1016/j.apsoil.2011.09.003

de Freitas JR, Banerjee MR, Germida JJ (1997) Phosphatesolubilizing rhizobacteria enhance the growth and yield but not phosphorus uptake of canola (Brassica napus). Biol Fertil Soils 36:842-855

De Lucia B, Vecchietti L (2012) Type of bio-stimulant and application method effects on stem quality and root system growth in L.A. Lily. Eur J Hortic Sci 77:10-15

Dobbss LB, Canellas LP, Olivares FL et al (2010) Bioactivity of chemically transformed humic matter from vermicompost on plant root growth. J Agric Food Chem 58:3681-3688

Dobbss LB, Medici LO, Peres LEP et al (2007) Changes in root development of Arabidopsis promoted by organic matter from oxisosis. Ann Appl Biol 151:199-211

Döbbelaere S, Croonenborghs A, Thys A, Vande Broek A, Vanderleyden J (1999) Phytostimulatory effect of Azospirillum brasilense wild type and mutant strains altered in IAA production on wheat. Plant Soil 212:153-162. doi:10. 1023/a:1004658000815

Döbereiner J (1997) Biological nitrogen fixation in the tropics: social and economic contributions. Soil Biol Biochem 29:771-774

Dodd IC, Pérez-Alfocea F (2012) Microbial amelioration of crop salinity stress. J Exp Bot 63:3415-3428. doi:10.1093/jxb/ ers033

Dodd IC, Ruiz-Lozano JM (2012) Microbial enhancement of crop resource use efficiency. Curr Opin Biotechnol 23:236-242. doi:10.1016/j.copbio.2011.09.005

Dodd IC, Zinovkina NY, Safronova VI, Belimov AA (2010) Rhizobacterial mediation of plant hormone status. Ann
Appl Biol 157:361-379. doi:10.1111/j.1744-7348.2010. 00439. $\mathrm{x}$

dos Reis SP, Lima AM, de Souza CRB (2012) Recent molecular advances on downstream plant responses to abiotic stress. Int J Mol Sci 13:8628-8647

du Jardin, P., 2012. The science of plant biostimulants-a bibliographic analysis. Contract 30-CE0455515/00-96, ad hoc Study on bio-stimulants products. http://ec.europa.eu/ enterprise/sectors/chemicals/files/fertilizers/final_report_ bio_2012_en.pdf

Dunstone RL, Richards RA, Rawson HM (1988) Variable responses of stomatal conductance, growth, and yield to fulvic acid applications to wheat. Aust J Agric Res 39:547-553

Egamberdiyeva D, Höflich G (2004) Effect of plant growthpromoting bacteria on growth and nutrient uptake of cotton and pea in a semi-arid region of Uzbekistan. J Arid Environ 56:293-301. doi:10.1016/S0140-1963(03)00050-8

Einset J, Nielson E, Connolly EL et al (2007) Membranetrafficking RabA4c involved in the effect of glycine betaine on recovery from chilling stress in Arabidopsis. Physiol Plant 130:511-518

Einset J, Winge P, Bones AM, Connolly EL (2008) The FRO2 ferric reductase is required for glycine betaine's effect on chilling tolerance in Arabidopsis roots. Physiol Plant 134: 334-341

El-Nemr MA, El-Desuki M, El-Bassiony AM, Fawzy ZF (2012) Response of growth and yield of cucumber plants (Cucumis sativus L.) to different foliar applications of humic acid and bio-stimulators. Aust J Basic Appl Sci 6:630-637

Ertani A, Cavani L, Pizzeghello D et al (2009) Biostimulant activity of two protein hydrolyzates in the growth and nitrogen metabolism of maize seedlings. J Plant Nutri Soil Sci 172:237-244

Ertani A, Pizzeghelio D, Altissimo A, Nardi S (2013a) Use of meat hydrolyzate derived from tanning residues as plant biostimulant for hydroponically grown maize. J Plant Nutr Soil Sci 176:287-296

Ertani A, Schiavon M, Muscolo A, Nardi S (2013b) Alfalfa plantderived biostimulant stimulate short-term growth of salt stressed Zea mays L. plants. Plant Soil 364:145-158

Esteves da Silva JCG, Machado AASC, Oliveira CJS (1998) Effect of $\mathrm{pH}$ on complexation of $\mathrm{Fe}(\mathrm{III})$ with fulvic acids. Environ Toxicol Chem 17:1268-1273

European Biostimulants Industry Council (2013) Economic overview of the biostimulants sector in Europe,17 April 2013. http://www.biostimulants.eu/wp-content/uploads/2013/04/ Biostimulant_economics_17April2013.pdf

European Biostimulants Industry Council (2012a) EBIC and biostimulants in brief. http://www.biostimulants.eu/

European Biostimulants Industry Council (2012b) What are biostimulants? http://www.biostimulants.eu/about/what-arebiostimulants/

Evelin H, Kapoor R, Giri B (2009) Arbuscular mycorrhizal fungi in alleviation of salt stress: a review. Ann Bot 104: 1263-1280

Eyheraguibel B, Silvestre J, Morard P (2008) Effects of humic substances derived from organic waste enhancement on the growth and mineral nutrition of maize. Bioresour Technol 99: 4206-4212

Fan D, Hodges DM, Critchley AT, Prithiviraj B (2013) A commercial extract of Brown Macroagla (Ascophyllum nodosum) 
affects yield and the nutritional quality of spinach in vitro. Commun Soil Sci Plant Anal 44:1873-1884

Fan X, Gordon-Weeks R, Shen Q, Miller AJ (2006) Glutamine transport and feedback regulation of nitrate reductase activity in barley roots leads to changes in cytosolic nitrate pools. J Exp Bot 57:1333-1340

Fayez M, Daw ZY (1987) Effect of inoculation with different strains of Azospirillum brasilense on cotton (Gossypium barbadense). Biol Fertil Soils 4:1-95

Feller C, Brossard M, Chen Y, Landa ER, Trichet J (2010) Selected pioneering works on humus in soils and sediments during the 20th century: a retrospective look from the International Humic Substances Society view. Phys Chem Earth 35:903-912

Feng G, Zhang F, Li X et al (2002) Improved tolerance of maize plants to salt stress by arbuscular mycorrhiza is related to higher accumulation of soluble sugars in roots. Mycorrhiza 12:185-190. doi:10.1007/s00572-002-0170-0

Fernando WGD, Ramarathnam R, Krishnamoorthy AS, Savchuk SC (2005) Identification and use of potential bacterial organic antifungal volatiles in biocontrol. Soil Biol Biochem 37: 955-964

Forde BG, Lea PJ (2007) Glutamate in plants: metabolism, regulation, and signalling. J Exp Bot 58:2339-2358

Frankenberger JWT, Arshad M (1995) Phytohormones in soils. Dekker, New York

Friedrich S, Platonova NP, Karavaiko GI, Stichel E, Glombitza F (1991) Chemical and microbiological solubilization of silicates. Acta Biotechnolog 11:187-196. doi:10.1002/abio. 370110302

Fulchieri M, Lucangeli C, Bottini R (1993) Inoculation with Azospirillum lipoferum affects growth and gibberellin status of corn seedling roots. Plant Cell Physiol 34: 1305-1309

Furuya S, Umemiya Y (2002) The influence of chemical forms on foliar-applied nitrogen absorption for peach trees. Acta Hortic 594:97-103

Gamalero E, Berta G, Glick B (2009) The use of microorganisms to facilitate the growth of plants in saline soils. In: Khan MS, Zaidi A, Musarrat J (eds) Microbial strategies for crop improvement. Springer, Berlin Heidelberg, pp 1-22

Gajc-Wolska J, Kowalczyk K, Nowecka M, Mazur K, Metera A (2012) Effect of organic-mineral fertilizers on the yield and quality of Endive (Cichorium endivia L.). Acta Sci Pol 11: 189-200

Garcia de Salamone IEG, Dobereiner J, Urquiaga S, Boddey RM (1996) Biological nitrogen fixation in Azospirillum strainmaize genotype associations as evaluated by the ${ }^{15} \mathrm{~N}$ isotope dilution technique. Biol Fertil Soils 23:249-256

García de Salamone IE, Hynes RK, Nelson LM (2001) Cytokinin production by plant growth promoting rhizobacteria and selected mutants. Can J Microbiol 47:404-411

García AC, Berbara RLL, Farías LP et al (2012) Humic acids of vermicompost as an ecological pathway to increase resistance of rice seedlings to water stress. Afr J Biotechnol 11: 3125-3134

García AC, Santos LA, Izquierdo FG et al (2013) Potentialities of vermicompost humic acids to alleviate water stress in rice plants (Oryza sativa L.). J Geochem Explor 136:48-54

García-Martínez AM, Díaz A, Tejada M et al (2010) Enzymatic production of an organic soil biostimulant from wheat- condensed distiller solubles: effects on soil biochemistry and biodiversity. Process Biochem 45:1127-1133

Giri B, Mukerji KG (2004) Mycorrhizal inoculant alleviates salt stress in Sesbania aegyptiaca and Sesbania grandiflora under field conditions: evidence for reduced sodium and improved magnesium uptake. Mycorrhiza 14:307-312. doi:10.1007/ s00572-003-0274-1

Glick BR, Penrose DM, Li J (1998) A model for the lowering of plant ethylene concentrations by plant growth-promoting bacteria. J Theor Biol 190:63-68

Glick BR, Todorovic B, Czarny J, Cheng Z, Duan J (2007) Promotion of plant growth by bacterial ACC deaminase. Crit Rev Plant Sci 26:227-242

Goldstein AH (1995) Recent progress in understanding the molecular genetics and biochemistry of calcium phosphate solubilization by Gram negative bacteria. Biol Agric Hort 12: 185-193

González A, Castro J, Vera J, Moenne A (2013) Seaweed oligosaccharides stimulate plant growth by enhancing carbon and nitrogen assimilation, basal metabolism, and cell division. $\mathrm{J}$ Plant Growth Regul 32:443-448

Grabowska A, Kunicki E, Sekara A, Kalisz A, Wojciechowska R (2012) The effect of cultivar and biostimulant treatment on the carrot yield and its quality. Veg Crops Res Bull 77:37-48

Grandlic CJ, Mendez MO, Chorover J, Machado B, Maier RM (2008) Plant growth-promoting bacteria for phytostabilization of mine tailings. Environ SciTechnol 42:2079-2084

Gügi B, Orange N, Hellio F et al (1991) Effect of growth temperature on several exported enzyme activities in the psychrotropic bacterium Pseudomonas fluorescens. J Bacteriol 173:3814-3820

Gu Z, Wang X, Gu X et al (2001) Effects of fulvic acid on the bioavailability of rare earth elements and GOT enzyme activity in wheat (Triticum aestivum). Chemosphere 44:545-551

Gupta V, Kumar M, Brahmbhatt H et al (2011) Simultaneous determination of different endogenetic plant growth regulators in common green seaweeds using dispersive liquid-liquid microextraction method. Plant Physiol Biochem 49:1259-1263

Gutiérrez-Mañero FJ, Ramos-Solano B, Probanza AN, Mehouachi J, Tadeo FR, Talon M (2001) The plant-growthpromoting rhizobacteria Bacillus pumilus and Bacillus licheniformis produce high amounts of physiologically active gibberellins. Physiol Plant 111:206-211. doi:10.1034/j.139954.2001.1110211.x

Gyaneshwar P, Naresh Kumar G, Parekh LJ, Poole PS (2002) Role of soil microorganisms in improving $\mathrm{P}$ nutrition of plants. Plant Soil 245:83-93. doi:10.1023/a:1020663916259

Hamaoui B, Abbadi JM, Burdman S et al (2001) Effects of inoculation with Azospirillum brasilense on chickpeas (Cicer arietinum) and faba beans (Vicia faba) under different growth conditions. Agronomie 21:553-560

Han HS, Lee KD (2005) Phosphate and potassium solubilizing bacteria effect on mineral uptake, soil availability and growth of eggplant. Res J Agric Biol Sci 1:176-180

Harper SM, Edwards DG, Kerven GL, Asher CJ (1995) Effects of organic acid fractions extracted from Eucalyptus camaldulensis leaves on root elongation of maize (Zea mays) in the presence and absence of aluminium. Plant Soil 171:189-192

Hartmann A, Bashan Y (2009) Ecology and application of Azospirillumand other plant growth-promoting bacteria (PGPB) - special issue. Eur J Soil Biol 45:1-2 
Hayat R, Ali S, Amara U, Khalid R, Ahmed I (2010) Soil beneficial bacteria and their role in plant growth promotion: a review. Ann Microbiol 60:579-598

Herve RA, Rouillier DL (1977) Method and apparatus for communiting (sic) marine algae and the resulting product United States Patent 4,023,734

Hirayama T, Shinozaki K (2010) Research on plant abiotic stress responses in the post-genome era: past, present and future. Plant J 61:1041-1052

Hong DD, Hien HM, Son PN (2007a) Seaweeds from Vietnam used for functional food, medicine and biofertilizer. J Appl Phycol 19:817-826

Honma M (1993) Stereospecific reaction of 1-aminocyclopropane1-carboxylate deaminase. In: Pech JC, Latche A, Balague C (eds) Cellular and molecular aspects of the plant hormone ethylene. Kluwer, Dordrecht, pp 111-116

Hong DD, Hien HM, Son PN (2007b) Seaweeds from Vietnam used for functional food, medicine and biofertilizer. J Appl Phycol 19:817-826

Hu C, Qi YC (2013) Long-term effective microorganisms application promote growth and increase yields and nutrition of wheat in China. Eur J Agron 46:63-67

Huang T, Jander G, de Vos M (2011) Non-protein amino acids in plant defense against insect herbivores: representative cases and opportunities for further functional analysis. Phytochemistry 72:1531-1537

Hurek TB, Reinhold-Hurek B, Montagu MB, Kellenberger E (1994) Root colonization and systematic spreading of Azoarcus sp strain BH72 in grasses. J Bacteriol 176: 1913-1923

Hussain A, Hasnain S (2009) Cytokinin production by some bacteria: Its impact on cell division in cucumber cotyledons. Afr J Microbiol Res 3:704-712

Idris EE, Iglesias EJ, Talon M, Borriss R (2007) Tryptophandependent production of indole-3-acetic acid (IAA) affects level of plant growth promotion by Bacillus amyloliquefaciens FZB42. Mol Plant-Microbe Interact 20: 619-626

Idriss EE, Makarewicz O, Farouk A et al (2002) Extracellular phytase activity of Bacillus amyloliquefaciens FZB45 contributes to its plant-growth-promoting effect. Microbiology 148:2097-2109

Jakab G, Ton J, Flors V et al (2005) Enhancing Arabidopsis salt and drought stress tolerance by chemical priming for its abscisic acid responses. Plant Physiol 139:267-274

Jakobsen I, Chen BD, Munkvold L, Lundsgaard T, Zhu YG (2005) Contrasting phosphate acquisition of mycorrhizal fungi with that of root hairs using the root hairless barley mutant. Plant Cell Environ 28:928-938

Jannin L, Arkoun M, Etienne P et al (2013) Brassica napus growth is promoted by Ascophyllum nodosum (L.) Le Jol. seaweed extract: microarray analysis and physiological characterization of N, C, and S metabolisms. J Plant Growth Regul 32: $31-52$

Jannin L, Arkoun M, Ourry A et al (2012) Microarray analysis of humic acid effects on Brassica napus growth: involvement of $\mathrm{N}, \mathrm{C}$ and $\mathrm{S}$ metabolisms. Plant Soil 359:297-319

Jeannin I, Lescure JC, Morot-Gaudry JF (1991) The effects of aqueous seaweed sprays on the growth of maize. Bot Mar 334:469-473
Jindo K, Martim SA, Navarro EC et al (2012) Root growth promotion by humic acids from composted and noncomposted urban organic wastes. Plant Soil 353:209-220

Jithesh MN, Wally OSD, Manfield I et al (2012) Analysis of seaweed extract-induced transcriptime leads to identification of a negative regulator of salt tolerance in Arabidopsis. Hortscience 47:704-709

Kannapiran E, Ramkuma VS (2011) Isolation of phosphate solubilizing bacteria from sediments of Thondi coast, Palk Strait, Southeast Coast India. Ann Biol Res 2:157-163

Karakurt Y, Unlu H, Unlu H, Padem H (2009) The influence of foliar and soil fertilization of humic acid on yield and quality of pepper. Acta Agric Scand Sect B 59:233-237

Karlidag H, Turan M, Pehluvan M, Donmez F (2013) Plant growth-promoting rhizobacteria mitigate deleterious effects of salt stress on strawberry plants (Fragaria $\times$ ananassa). Hort Science 48:563-567

Kauffman GL III, Kneivel DP, Watschke TL (2005) Growth regulator activity of Macro-Sorb ${ }^{\circledR}$ Foliar in vitro. PGRSA Q 33:134-141

Kauffman GL III, Kneival DP, Watschke TL (2007) Effects of biostimulant on the heat tolerance associated with photosynthetic capacity, membrane thermostability, and polphenol production of perennial ryegrass. Crop Sci 47:261-267

Kaushik R, Saxena AK, Tilak KVBR (2000) Selection of Tn5:: lacZ mutants isogenic to wild type Azospirillum brasilense strains capable of growing at sub-optimal temperature. World J Microbiol Biotechnol 16:567-570. doi:10.1023/ a:1008901331991

Kelleher BP, Simpson AJ (2006) Humic substances in soils: are they really chemically distinct? Environ Sci Technol 40: 4605-4611

Kemmerling B, Halter T, Mazzotta S, Mosher S, Nürnberger T (2011) A genome-wide survey for Arabidopsis leucine-rich repeat receptor kinases implicated in plant immunity. Front Plant Sci 2:1-6

Kerkeb L, Krämer U (2003) The role of free histidine in xylem loading of nickel in Alyssum lesbiacum and Brassica juncea. Plant Physiol 131:716-724

Khalid A, Arshad M, Kahir ZA (2004) Screening plant growthpromoting rhizobacteria for improving growth and yield of wheat. Appl Soil Ecol 96:473-480

Khaliq A, Abbasi MK, Hussain T (2006) Effect of integrated use of organic and inorganic nutrient sources with effective microorganisms (EM) on seed cotton yield in Pakistan. Bioresour Technol 97:967-972

Khan AG (2005) Role of soil microbes in the rhizospheres of plants growing on trace metal contaminated soils in phytoremediation. J Trace Elements Med Biol 18:355-364

Khan W, Hiltz D, Critchley AT, Prithiviraj B (2011a) Bioassay to detect Ascophyllum nodosum extract-induced cytokinin-like activity in Arabidopsis thaliana. J Appl Phycol 23:409-414

Khan ZH, Kahn MA, Aftab T, Idrees M, Naeem M (2011b) Influence of alginate oligosaccharides on growth, yield and alkaloid production of opium poppy (Papaver somniferum L.). Front Agric China 5:122-127

Khan W, Palanisamy R, Critchley AT, Smith DL, Papadopoulos Y (2013) Prithiviraj AT (2013) Ascophyllum nodosum extract and its organic fractions stimulate rhizobium root nodulation and growth of Medicago sativa (Alfalfa). Commun Soil Sci Plant Anal 44:900-908 
Khan W, Rayirath UP, Subramanian S et al (2009) Seaweed extracts as biostimulants of plant growth and development. J Plant Growth Regul 28:386-399

Khan W, Zhai R, Souleimanov A et al (2012) Commercial extract of Ascophyllum nodosum improves root colonization of alfalfa by its bacterial symbiont Sinorhizobium meliloti. Commun Soil Sci Plant Anal 43:2425-2436

Kim Y-C, Glick B, Bashan Y, Ryu C-M (2012) Enhancement of plant drought tolerance by microbes. In: Aroca R (ed) Plant responses to drought stress. Springer-Verlag, Berlin Heidelberg, pp 383-413

Kinnersley AM, Turano FJ (2000) Gamma Aminobutyric Acid (GABA) and plant responses to stress. Crit Rev Plant Sci 19: 479-509

Kirn A, Kashif SR, Yaseen M (2010) Using indigenous humic acid from lignite to increase growth and yield of okra (Abelmoschus esculentus L.). Soil Environ 29:187-191

Klarzynski O, Descamps V, Plesse B et al (2003) Sulfated fucan oligosaccharides elicit defense responses in tobacco and local and systemic resistance against Tobacco Mosaic Virus. Mol Plant-Microbe Interact 16:115-122

Kloepper JW, Lifshitz R, Zablotowicz RM (1989) Free living bacterial inocula for enhancing crop productivity. Trends Biotechnol 7:39-44

Kohler J, Hernandez JA, Caravaca F, Roldan A (2008) Plantgrowth-promoting rhizobacteria and arbuscular mycorrhizal fungi modify alleviation biochemical mechanisms in waterstressed plants. Funct Plant Biol 35:141-151

Koukounararas A, Tsouvaltzis P, Siomos AS (2013) Effect of root and foliar application of amino acids on the growth and yield of greenhouse tomato in different fertilization levels. J Food, Agric Environ 11:644-648

Kpomblekou K, Tabatabai MA (1994) Effect of organic acids on release of phosphorus from phosphate rocks. Soil Sci Soc Am J 158:442-453

Kramer PJ, Boyer JS (1997) Water relations of plants and soils. Elsevier, San Diego

Krajnc AU, Ivanuš A, Kristl J, Šušek A (2012) Seaweed extract elicits the metabolic responses in leaves and enhances growth of Pelargonium cuttings. Europ J Hort Sci 77: 170-181

Krämer U, Cotter-Howells JD, Charnock JM, Baker AJM, Smith JAC (1996) Free histidine as a metal chelator in plants that accumulate nickel. Nature 379:635-638

Krasensky J, Jonak C (2012) Drought, salt, and temperature stressinduced metabolic rearrangements and regulatory networks. J Exp Bot 63:1593-1608

Krouk G, Lacombe B, Bielach A et al (2010) Nitrate-regulated auxin transport by NRT1.1 defines a mechanism for nutrient sensing in plants. Dev Cell 18:927-937

Kucey RMN (1988) Plant growth-altering effects of Azospirillum brasilense and Bacillus C-11-25 on two wheat cultivars. J Appl Bacteriol 64:187-196

Kuiper I, Lagendijk EL, Bloemberg GV, Lugtenberg BJJ (2004) Rhizoremediation: a beneficial plant-microbe interaction. Mol Plant Microbe Interact 17:6-15

Kumar G, Sahoo D (2011) Effect of seaweed liquid extract on growth and yield of Triticum aestivum var. Pusa Gold J Appl Phycol 23:251-255

Kumari R, Kaur I, Bhatnagar AK (2011) Effect of aqueous extract of Sargassum johnstonii Setchell\& Gardner on growth, yield and quality of Lycopersicon esculentum Mill. J Appl Phycol 23:623-633

Kunicki E, Grabowska A, Sękara A, Wojciechowska R (2010) The effect of cultivar type, time of cultivation, and biostimulant treatment on the yield of spinach (Spinacia oleracea L). Folia Hortic 22:9-13

Kuwada K, Ishii T, Matsushita I, Matsumoto I, Kadoya K (1999) Effect of seaweed extracts on hyphal growth of vesiculararbuscular mycorrhizal fungi and their infectivity on trifoliate orange roots. J Japan Soc Hort Sci 68:321-326

Lamar R, Olk DC, Mayhew L, Bloom PR (2013) Evaluation of a proposed standardized analytical method for the determination of humic and fulvic acids in commercial products. In: $\mathrm{Xu} \mathrm{J}, \mathrm{Wu}$ J, He Y (eds) Functions of natural organic matter in changing environment. Zhejiang University Press and Springer Science+Business Media, Dordrecht, pp 1071-1073

Lea PJ, Sodek L, Parry MAJ, Shewry PR, Halford NG (2006) Asparagine in plants. Ann Appl Biol 150:1-26

Leyval C, Turnau K, Haselwandter K (1997) Effect of heavy metal pollution on mycorrhizal colonization and function: physiological, ecological and applied aspects. Mycorrhiza 7: $139-153$

Liang XW, Zhang L, Natarajan SK, Beckker DF (2013) Proline Mechanisms of stress survival. Antioxid Redox Signaling 19: 998-1011

Lobartini JC, Tan KH, Pape C (1998) Dissolution of aluminum and iron phosphate by humic acids. Commun Soil Sci Plant Anal 29:535-544

Lola-Luz T, Hennequart F, Gaffney M (2013) Enhancement of phenolic and flavonoid compounds in cabbage (Brassica oleraceae) following application of commercial seaweed extracts of the brown seaweed (Ascophyllum nodosum). Agric Food Sci 22:288-295

Liu A, Hamel C, Hamilton RI, Ma BL, Smith DL (2000) Acquisition of $\mathrm{Cu}, \mathrm{Zn}, \mathrm{Mn}$ and $\mathrm{Fe}$ by mycorrhizal maize (Zea mays L.) grown in soil at different $\mathrm{P}$ and micronutrient levels. Mycorrhiza 9:331-336. doi:10.1007/s005720050277

Lulakis MD, Petsas SI (1995) Effect of humic substances from vine-canes mature compost on tomato seedling growth. Bioresour Technol 54:179-182

Ma Y, Prasad MNV, Rajkumar M, Freitas H (2011) Plant growth promoting rhizobacteria and endophytes accelerate phytoremediation of metalliferous soils. Biotechnol Adv 29: 248-258

Ma Y, Rajkumar M, Freitas H (2009) Inoculation of plant growth promoting bacterium Achromobacter xylosoxidans strain Ax10 for the improvement of copper phytoextraction by Brassica juncea. J Environ Manage 90:831-837. doi:10. 1016/j.jvman.2008.01.014

MacDonald JE, Hacking J, Weng Y, Norrie J (2012) Root growth of containerized lodgepole pine seedlings in response to Ascophyllum nodosum extract application during nursery culture. Can J Plant Sci 92:1207-1212

Maini P (2006) The experience of the first biostimulant, based on amino acids and peptides: a short retrospective review on the laboratory researches and the practical results. Fertilitas Agrorum 1:29-43

Malboobi MA, Behbahani M, Madani H et al (2009) Performance evaluation of potent phosphate solubilizing bacteria in potato rhizosphere. World J Microbiol Biotechnol 25:1479-1484 
Malik KA, Mirza MS, Hassan U, Mehnaz S, Rasul G, Haurat J, Bauy R, Normanel P (2002) The role of plant associated beneficial bacteria in rice-wheat cropping system. In: Kennedy IR, Chaudhry A (eds) Biofertilisers in action. Rural Industries Research and Development Corporation, Canberra, pp 73-83

Mancuso S, Azzarello E, Mugnai S, Briand X (2006) Marine bioactive substances (IPA extract) improve foliar ion uptake and water stress tolerance in potted Vitis vinifera plants. Adv Hortic Sci 20:156-161

Marino G, Cellini A, Masia A et al (2010) In vitro treatment with a low molecular weight humic acid can improve growth and mineral uptake of pear plantlets during acclimatization. Acta Hortic 884:565-572

Marulanda A, Barea J-M, Azcón R (2009) Stimulation of plant growth and drought tolerance by native microorganisms (AM fungi and bacteria) from dry environments:mechanisms related to bacterial effectiveness. J Plant Growth Regul 28:115124. doi:10.1007/s00344-009-9079-6

Mattner SW, Wite D, Riches DA, Porter IJ, Arioli T (2013) The effect of kelp extract on seedling establishment of broccoli on contrasting soil types in southern Victoria, Australia. Biol Agric Hortic 29:258-270

Mayak S, Tirosh T, Glick BR (2004) Plant growth-promoting bacteria that confer resistance to water stress in tomatoes and peppers. Plant Sci 166:525-530. doi:10.1016/j. plantsci2003.10. 025

Mayer J, Scheid S, Widmer F, Fließbach A, Oberholzer H-R (2010) How effective are 'effective microorganisms ${ }^{\circledR}$ (EM)'? Results from a field study in temperate climate. Appl Soil Ecol 46:230-239

Mazhar AAM, Shedeed SI, Abdel-Aziz NG, Mahgoub MH (2012) Growth, flowering and chemical constituents of Chrysanthemum indicum L. plant in response to different levels of humic acid and salinity. J Appl Sci Res 8:3697-3706

Mehnaz S, Mirza MS, Haurat J et al (2001) Isolation and 16S rRNA sequence analysis of the beneficial bacteria from the rhizosphere of rice. Can J Microbiol 472:110-117

Miller AJ, Fan X, Shen Q, Smith SJ (2007) Amino acids and nitrate as signals for the regulation of nitrogen acquisition. $\mathrm{J}$ Exp Bot 59:11-119

Milton RF (1952) Improvements in or relating to horticultural and agricultural fertilizers. The Patent Office London, no. 663, 989. $2 \mathrm{pp}$

Milton RF (1962) The production of compounds of heavy metals with organic residues. British Patent no. 902,563. 3 pp

Milton RF (1964) Liquid seaweed as a fertilizer. Proc Int Seaweed Symp 4:428-431

Moghaddam ARL, Soleimani A (2012) Compensatory effects of humic acid on physiological characteristics of pistachio seedlings under salinity stress. Acta Hortic 940:252-255

Mohamed WH (2012) Effects of humic acid and calcium forms on dry weight and nutrient uptake of maize plant under saline condition. Aust J Basic Appl Sci 6:597-604

Mora V, Bacaicoa E, Zamarreño A-M et al (2010) Action of humic acid on promotion of cucumber shoot growth involves nitrate-related changes associated with the root-to-shoot distribution of cytokinins, polyamines and mineral nutrients. J Plant Physiol 167:633-642

Morales-Payan JP, Stall WM (2003) Papaya (Carica papaya) response to foliar treatments with organic complexes of peptides and amino acids. Proc Fla State Hortic Soc 116:30-32
Morard P, Eyheraguibel B, Morard M, Silvestre J (2011) Direct effects of humic-like substance on growth, water, and mineral nutrition of various species. J of Plant Nutr 34:46-59

Mrkovacki N, Milic V (2001) Use of Azotobacter chroococcum as potentially useful in agricultural application. Ann Microbiol 51:145-158

Mugnai S, Azzarello E, Pandolfi C et al (2008) Enhancement of ammonium and potassium root influxes by the application of marine bioactive substances positively affects Vitis vinifera plant growth. J Appl Phycol 20:177-182

Murillo JM, Madejón E, Madejón P, Cabrera F (2005) The response of wild olive to the addition of a fulvic acid-rich amendment to soils polluted by trace elements (SW Spain). J Arid Environ 63:284-303

Muscolo A, Sidari M, Francioso O, Tugnoli V, Nardi S (2007) The auxin-like activity of humic substances is related to membrane interactions in carrot cell cultures. J Chem Ecol 33: $115-129$

Nabati DA, Schmidt RE, Parrish DJ (1994) Alleviation of salinity stress in Kentucky Bluegrass by plant growth regulators and iron. Crop Sci 34:198-202

Nacry P, Bouguyon E, Gojon A (2013) Nitrogen acquisition by roots: physiological and developmental mechanisms ensuring plant adaptation to a fluctuating resource. Plant Soil 370: $1-29$

Nair P, Kandasamy S, Zhang J et al (2012) Transcriptional and metabolomics analysis of Ascophyllum nodosum mediated freezing tolerance in Arabidopsis thaliana. BMC Genomics 13:643. doi:10.1186/1471-2164-13-643

Nardi S, Arnoldi G, Dell'Agnola G (1988) Release of hormonelike activities from Allolobophora rosea (Sav.) and Allolobophora calignosa (Sav.) feces. Can J Soil Sci 68: 563-567

Nardi S, Carletti P, Pizzeghello D, Muscolo A (2009) Biological activities of humic substances. In: Senesi N, Xing B, Huang PM (eds) Biophysico-chemical processes involving natural nonliving organic matter in environmental systems. Wiley, Hoboken, pp 305-339

Nardi S, Concheri G, Dell'Agnola G (1996) Biological activity of humus. In: Piccolo A (ed) Humic substances in terrestrial ecosystems. Elsevier, Amsterdam, pp 361-406

Nardi S, Pizzeghello D, Muscolo A, Vianello A (2002) Physiological effects of humic substances on higher plants. Soil Biol Biochem 34:1527-1536

Nardi S, Pizzeghello D, Reniero F, Rascio N (2000) Chemical and biochemical properties of humic substances isolated from forest and plant growth. Soil Soc Am J 64:639-645

Nardi S, Reniero F, Concheri G (1997) Soil organic matter mobilization by root exudates of three maize hybrids. Chemosphere 35:2237-2244

Neilands JB, Nakamura K (1991) Detection, determination, isolation, characterization and regulation of microbial iron chelates. In: Winkelman G (ed) CRC Handbook of microbial iron chelates. CRC Press, Boca Raton, FL, pp 1-14

Norrie J, Keathley JP (2006) Benefits of Ascophyllum nodosum marine-plant extract applications to "Thompson seedless' grape production. Acta Hortic 727:243-247

Omar MNA, Mahrous NM, Hamouda AM (1996) Evaluating the efficiency of inoculating some diazatrophs on yield and protein content of 3 wheat cultivars under graded levels of nitrogen fertilization. Ann Agric Sci 41:579-590 
Ortíz-Castro R, Contreras-Cornejo HA, Macías-Rodríguez L, López-Bucio J (2009) The role of microbial signals in plant growth and development. Plant Signaling Behav 4:701-712

Padilla FM, Pugnaire FI (2007) Rooting depth and soil moisture control Mediterranean woody seedling survival during drought. Funct Ecol 21:489-495. doi:10.1111/j.1365-2435. 2007.01267.x

Pan IL, McQuinn R, Giovannoni JJ, Irish VF (2010) Functional diversification of AGAMOUS lineage genes in regulating tomato flower and fruit development. J Exp Bot 61:1795-1806

Pandeya SB, Singh AK, Dhar P (1998) Influence of fulvic acid on transport of iron in soils and uptake by paddy seedlings. Plant Soil 198:117-125

Park KH, Lee CY, Son HJ (2009) Mechanism of insoluble phosphate solubilization by Pseudomonas fluorescens RAF15 isolated from ginseng rhizosphere and its plant growth-promoting activities. Lett Appl Microbio 49: 222-228

Park M, Kim C, Yang J et al (2005) Isolation and characterization of diazotrophic growth promoting bacteria from rhizosphere of agricultural crops of Korea. Microbiol Res 160:127-133

Parmar P, Sindhu SS (2013) Potassium solubilization by rhizosphere bacteria: influence of nutritional and environmental conditions. J Microbiol Res 3:25-31

Parrado J, Bautista J, Romero EF et al (2008) Production of a carob enzymatic extract: Potential use as a biofertilizer. Bioresour Technol 99:2312-2318

Peng A, Xu Y, Wang ZJ (2001) The effect of fulvic acid on the dose effect of selenite on the growth of wheat. Biol Trace Elem Res 83:275-279

Pérez-Alfocea F, Albacete A, Ghanem ME, Dodd IC (2010) Hormonal regulation of source-sink relations to maintain crop productivity under salinity: A case study of root-toshoot signalling in tomato. Funct Plant Biol 37:592-603

Piccoli P, Lucangeli D, Schneider G, Bottini R (1997) Hydrolysis of [17,17-2H2]Gibberellin A20-Glucoside and [17,172H2]Gibberellin A20-glucosyl ester by Azospirillum lipoferum cultured in a nitrogen-free biotin-based chemically-defined medium. Plant Growth Regul 23:179-182

Piccolo A (2001) The supramolecular structure of humic substances. Soil Sci 166:810-832

Piccolo A, Conte P, Spaccini R, Chiarella M (2003) Effects of some dicarboxylic acids on the association of dissolved humic substances. Biol Fertil Soils 37:255-259

Piccolo A, Conte P, Trivellone E, Van Lagen B, Buurman P (2002) Reduced heterogeneity of a lignite humic acid by preparative HPSEC following interaction with an organic acid. Characterization of size-separates by Pyr-GC-MS and H-NMR spectroscopy. Environ Sci Technol 36:76-84

Piccolo A, Nardi S, Concheri G (1992) Structural scharacteristics of humic substances as related to nitrate uptake and growth regulation in plant systems. Soil Biol Biochem 24:373-380

Piccolo A, Spiteller M (2003) Electrospray ionization mass spectrometry of terrestrial humic substances and their size fractions. Anal Bioanal Chem 377:1047-1059

Pimentel JP, Olivares F, Pitard RM et al (1991) Dinitrogen fixation and infection of grass leaves by Pseudomonas rubrisubalbicans and Herbaspirillum seropedicae. Dev Plant Soil Sci 48:225-229
Pinton R, Cesco S, Iacolettig G, Astolfi S, Varanini Z (1999) Modulation of $\mathrm{NO}_{3}{ }^{-}$uptake by water-extractable humic substances: involvement of root plasma membrane $\mathrm{H}^{+}$ATPase. Plant Soil 215:155-161

Pinton R, Cesco S, Santi S, Varanini Z (1997) Effect of humic substances stimulate proton release by intact oat seedling roots. J Plant Nutr 20:857-869

Poapst PA, Schnitzer M (1971) Fulvic acid and adventitious root formation. Soil Biol Biochem 3:215-219

Porcel R, Aroca R, Ruiz-Lozano JM (2012) Salinity stress alleviation using arbuscular mycorrhizal fungi. Agron Sustainable Dev 32:181-200

Quaggiotti S, Rupertri B, Pizzeghello D et al (2004) Effect of low molecular size humic substances on the expression of genes involved in nitrate transport and reduction in maize (Zea mays L.). J Exp Bot 55:803-813

Querejeta JI, Barea JM, Allen MF, Caravaca F, Roldan A (2003) Differential response of $\delta^{13} \mathrm{C}$ and water use efficiency to arbuscular mycorrhizal infection in two arid land woody plant species. Oecologia 135:510-515

Quilty JR, Cattle SR (2011) Use and understanding of organic amendments in Australian agriculture: a review. Soil Res 49: $1-26$

Rathore SS, Chaudhary DR, Boricha GN et al (2009) Effect of seaweed extract on the growth, yield and nutrient uptake of soybean (Glycine max) under rainfed conditions. S Afr J Bot 75:351-355

Rauthan BS, Schnitzer M (1981) Effects of a soil fulvic acid on the growth and nutrient content of cucumber (Cucumis sativus) plants. Plant Soil 63:491-495

Rayirath P, Benkel B, Hodges DM et al (2009) Lipophilic components of the brown seaweed, Ascophyllum nodosum, enhance freezing tolerance in Arabidopsis thaliana. Planta 230: $135-147$

Rayorath P, Jithesh MN, Farid A, Khan W, Palanisamy R, Hankins SD, Critchley AT, Prithiviraj B (2008) Rapid bioassays to evaluate the plant growth promoting activity of Ascophyllum nodosum (L.) Le Jol. using a model plant, Arabidopsis thaliana (L.) Heynh. J Appl Phycol 20:423-429

Reed MLE, Glick BR (2005) Growth of canola (Brassica napus) in the presence of plant growth-promoting bacteria and either copper or polycyclic aromatic hydrocarbons. Can J Microbiol 51:1061-1069

Reed MLE, Warner BG, Glick BR (2005) Plant growth-promoting bacteria facilitate the growth of the common reed Phargmites australis in the presence of copper or polycyclic aromatic hydrocarbons. Curr Microbiol 51:425-429

Remans S, Blair MW, Manrique G et al (2008) Physiological and genetic analysis of root responsiveness to auxin-producing plant growth-promoting bacteria in common bean (Phaseolus vulgaris L.). Plant Soil 302:149-161

Rice JA, MacCarthy P (1990) A model of humin. Environ Sci Technol 24:1875-1877

Richardson A, Barea J-M, McNeill A, Prigent-Combaret C (2009) Acquisition of phosphorus and nitrogen in the rhizosphere and plant growth promotion by microorganisms. Plant Soil 321:305-339. doi:10.1007/s11104-009-9895-2

Riggs PJ, Cheliu MK, Iniguez AL, Kaeppler SM, Triplett EW (2001) Enhanced maize productivity by inoculation with diazotrophic bacteria. Aust J Plant Physiol 28:829-836 
Rioux L-E, Turgeon SL, Beaulieu M (2007) Characterization of polysaccharides extracted from brown seaweeds. Carbohydr Polym 69:530-537

Rioux L-E, Turgeon SL, Beaulieu M (2009) Effect of season on the composition of bioactive polysaccharides from brown seaweed Saccharina longicruris. Phytochemistry 70:10691075

Rodriguez H, Fraga R (1999) Phosphate solubilizing bacteria and their role in plant growth promotion. Biotechnol Adv 17: 319-339, 0.1016/S0734-9750(99)00014-2

Rodríguez H, Fraga R, Gonzalez T, Bashan Y (2006) Genetics of phosphate solubilization and its potential applications for improving plant growth-promoting bacteria. Plant Soil 287: $15-21$

Rodríguez H, Gonzalez T, Goire I, Bashan Y (2004) Gluconic acid production and phosphate solubilization by the plant growthpromoting bacterium Azospirillum spp. Naturwissenschaften 91:552-555

Rodríguez H, Gonzalez T, Selman G (2001) Expression of a mineral phosphate solubilizing gene from Erwinia herbicola in two rhizobacterial strains. J Biotechnol 84:155-161

Rungin S, Indananda C, Suttiviriya P et al (2012) Plant growth enhancing effects by a siderophore-producing endophytic streptomycete isolated from a Thai jasmine rice plant (Oryza sativa L. cv. KDML105). Antonie Van Leeuwenhoek 102:463-472. doi:10.1007/s10482-0129778-z

Ryu C-M, Farag MA, Hu C-H et al (2003) Bacterial volatiles promote growth in Arabidopsis. Proc Natl Acad Sci U S A 100:4927-4932. doi:10.1073/pnas.0730845 100

Sahin F, Cakmakci R, Kantar F (2004) Sugar beet and barley yields in relation to inoculation with N2-fixing and phosphate solubilizing bacteria. Plant Soil 265:123-129

Saleem M, Arshad M, Hussain S, Bhatti A (2007) Perspective of plant growth promoting rhizobacteria (PGPR) containing ACC deaminase in stress agriculture. J Ind Microbiol Biotechnol 34:635-648. doi:10.1007/s10295-007-0240-6

Sánchez-Sánchez A, Sánchez-Andreu J, Juárez M, Jordá J, Bermúdez D (2002) Humic substances and amino acids improve effectiveness of chelate FeEDDHA in lemon trees. J Plant Nutr 25:2433-2442

Sánchez-Sánchez A, Sánchez-Andreu J, Juárez M, Jordá J, Bermúdez D (2006) Improvement of iron uptake in table grape by addition of humic substances. J Plant Nutr 29: 259-272

Sarfaraz A, Naeem M, Nasir S et al (2011) An evaluation of the effects of irradiated sodium alginate on the growth, physiological activities and essential oil production of fennel (Foeniculum vulgare Mill.). J Med Plants Res 5:15-21

Saubidet MI, Fatta N, Barneix AJ (2000) The effects of inoculation with Azospirillumbrasilense on growth and nitrogen utilization by wheat plants. Plant Soil 245:215-222

Schiavon M, Ertani A, Nardi S (2008) Effects of an alfalfa protein hydrolysate on the gene expression and activity of enzymes of the tricarboxylic acid (TCA) cycle and nitrogen metabolism in Zea mays L. J Agric Food Chem 56:11800-11808

Schiavon M, Pizzeghello D, Muscolo A, Vaccoro S, Francioso O, Nardi S (2010) High molecular size humic substances enhance phylpropanoid metabolism in maize (Zea mays L.). J Chem Ecol 36:662-669
Schweiger PF, Robson AD, Barrow NJ (1995) Root hair length determines beneficial effect of a Glomus species on shoot growth of some pasture species. New Phytol 131:247-254

Selim EM, Shaymaa IS, Asaad FF, El-Neklawy AS (2012) Interactive effects of humic acid and water stress on chlorophyll and mineral nutrient contents of potato plants. J Appl Sci Res 8:531-537

Shaharoona B, Naveed M, Arshad M, Zahir Z (2008) Fertilizerdependent efficiency of Pseudomonads for improving growth, yield, and nutrient use efficiency of wheat (Triticum aestivum L.). Appl Microbiol Biotechnol 79:147155. doi:10.1007/s00253-008-1419-0

Shahid M, Dumat C, Silvestre J, Pinelli E (2012) Effect of fulvic acids on lead-induced oxidative stress to metal sensitive Vicia faba L. plant. Biol Fertil Soils 48:689-697

Shang H, Shifeng C, Yang Z, Cai Y, Zheng Y (2011) Effect of exogenous $\gamma$-aminobutyric acid treatment on proline accumulation and chilling Injury in peach fruit after long-term cold storage. J Agric Food Chem 59:1264-1268

Sharma A, Shankhdar D, Shankhdhar SC (2013) Enhancing grain iron content of rice by the application of plant growth promoting rhizobacteria. Plant Soil Environ 59: 89-94

Sharma SHS, Lyons G, McRoberts C et al (2012) Biostimulant activity of brown seaweed species from Strangford Lough: compositional analyses of polysaccharides and bioassay of extracts using mung bean (Vigno mungo L.) and pak choi (Brassica rapa chinensis L.). J Appl Phycol 24:1081-1091

Sharma SS, Dietz K-J (2006) The significance of amino acids and amino acid-derived molecules in plant responses and adaptation to heavy metal stress. J Exp Bot 57:711-726

Sharp RE, Poroyko V, Hejlek LG et al (2004) Root growth maintenance during water deficits: physiology to functional genomics. J Exp Bot 55:2343-2351. doi:10.1093/jxb/ erh276

Shekhar SHS, Lyons G, McRoberts C et al (2012) Brown seaweed species from Strangford Lough: compositional analyses of seaweed species and biostimulant formulations by rapid instrumental methods. J Appl Phycol 24:1141-1157

Shelp BJ, Bown AW, McLean MD (1999) Metabolism and functions of gamma-aminobutyric acid. Trends Plant Sci 4:446-452

Sheng M, Tang M, Chen H et al (2008) Influence of arbuscular mycorrhizae on photosynthesis and water status of maize plants under salt stress. Mycorrhiza 18:287-296

Sheng XF, He LY (2006) Solubilization of potassium-bearing minerals by a wild-type strain of Bacillus edaphicus and its mutants and increased potassium uptake by wheat. Can J Microbiol 52:66-72

Simpson AJ, Kingery WL, Hayes MHB et al (2002) Molecular structures and associations of humic substances in the terrestrial enviornment. Naturwissenschaften 89:84 88

Singh B, Satyanarayana T (2011) Microbial phytases in phosphorus acquisition and plant growth promotion. Physiol Mol Biol Plants 17:93-103

Singh LP, Gill SS, Tuteja N (2011) Unraveling the role of fungal symbionts in plant abiotic stress tolerance. Plant Signaling Behav 6:175-191 
Sivasankari S, Venkatesalu V, Anantharaj M, Chandrasekaran M (2006) Effect of seaweed extracts on the growth and biochemical constituents of Vigna sinensis. Bioresour Technol 97:1745-1751

Slávik M (2005) Production of Norway spruce (Picea abies [L.] Karst.) seedlings on substrate mixes using growth stimulants. J For Sci 51:15-23

Smith SE, Jakobsen I, Grønlund M, Smith FA (2011) Roles of arbuscular mycorrhizas in plant phosphorus nutrition: interactions between pathways of phosphorus uptake in arbuscular mycorrhizal roots have important implications for understanding and manipulating plant phosphorus acquisition. Plant Physiol 156:1050-1057

Soldal T, Nissen P (1978) Multiphasic uptake of amino acids by barley roots. Physiol Plant 43:181-188

Spaepen S, Dobbelaere S, Croonenborghs A, Vanderleyden J (2008) Effects of Azospirillum brasilense indole-3-acetic acid production on inoculated wheat plants. Plant Soil 312: 15-23. doi:10.1007/s11104-008-9560-1

Spaepen S, Vanderleyden J, Okon Y (2009) Plant growthpromoting actions of rhizobacteria. Advances Bot Res 51: 283-320

Spinelli F, Fiori G, Noferini M, Sprocatti M, Costa G (2010) A novel type of seaweed extract as a natural alternative to the use of iron chelates in strawberry production. Sci Hortic 125: 263-269

Steinberg CEW, Meinelt T, Timofeyev MA, Bittner M, Menzel R (2008) Subject Area 2.1: Behavior of chemicals in water and their interactions with organisms. Environ Sci Pollut Res 15: 128-135

Stephenson WA (1974) Seaweed in agriculture \& horticulture, 3rd edition. B and G Rateaver (eds), Pauma Valley, CA

Stevenson FJ (1994) Humus chemistry: genesis, composition, reactions. Wiley, New York

Stiegler JC, Richardson MD, Karcher DE, Roberts TL, Norman RJ (2013) Foliar absorption of various inorganic and organic nitrogen sources by creeping bentgrass. Crop Sci 52:1148-1152

Stirk WA, Novák O, Strnad M, van Staden J (2003) Cytokinins in macroalgae. Plant Growth Regul 41:13-24

Stirk WA, van Staden J (1997) Comparison of cytokinin- and auxin-like activity in some commercially used seaweed extracts. J Appl Phycol

Stirk WA, van Staden J (2006) Seaweed products as biostimulatns in agriculture. In Critchley AT, Ohno M, Largo DB (eds) World seaweed resources [DVD-ROM]: ETI Information Services Lts, Univ. Amesterdam. ISBN: 9075000 80-4

Stoyanov I (1981) Restoration of maize plants after Magnesium starvation with the help of Magnesium and Siapton. Proc. 3rd Int. Symp. Plant Growth Regulators, Varna, Bulgaria (B.A.S., Sofia ed, publ. 1985), pp. 602-606.

Sutton R, Sposito G (2005) Molecular Structure in soil humic substances: the new view. Environ Sci Technol 39:9009-9015

Suzuki N, Koussevitzky S, Mittler R, Miller G (2012) ROS and redox signaling in the response of plants to abiotic stress. Plant Cell Environ 35:259-270

Sytar O, Kumar A, Latowski D et al (2013) Heavy metal-induced oxidative damage, defense reactions, and detoxification mechanisms in plants. Acta Physiol Plant 35:985-999

Tahir MM, Khurshid M, Khan MZ, Abbasi MK, Hazmi MH (2011) Lignite-derived humic acid effect on growth of wheat plants in different soils. Pedosphere 2:124-131
Tao GC, Tian SJ, Cai MY, Xie GH (2008) Phosphate-solubilizing and -mineralizing abilities of bacteria isolated from soils. Pedosphere 18:515-523

Tarafdar JC, Gharu A (2006) Mobilization of organic and poorly soluble phosphates by Chaetomium globosum. Appl Soil Ecol 32:273-283. doi:10.1016/j.apsoil.2005.08.005

Tarakhovskaya ER, Maslov YI, Shishova MF (2007) Phytohormones in algae. Russ J Plant Physiol 54:163-170

Temirov YV, Esikova TZ, Kashparov IA et al (2003) A catecholic siderophore produced by the thermoresistant Bacillus licheniformis VK21 Strain. Russ J Bioorg Chem 29:542549. doi:10.1023/B:RUBI.0000008894.80972.2e

Thaller MC, Berlutti F, Schippa S et al (1995) Heterogeneous patterns of acid phosphatases containing low-molecularmass polypeptides in members of the family Enterobacteriaceae. Int J Syst Evol Microbiol 4:255-261

Thompson JP (1987) Decline of vesicular-arbuscular mycorrhizae in long fallow disorder of field crops and its expression in phosphorus deficiency of sunflower. Aust J Agric Res 38: 847-867

Trevisan S, Botton A, Vaccaro S et al (2011) Humic substances affect Arabidopsis physiology by altering the expression of genes involved in primary metabolism, growth and development. Environ Exp Bot 74:45-55

Trevisan S, Francioso O, Quaggiotti S, Nardi S (2010) Humic substances biological activity at the plant-soil interface. Plant Signaling Behav 5:635-643

Tsukagoshi H, Busch W, Benfey P (2010) Transcriptional regulation of ROS controls transition from proliferation to differentiation in the root. Cell 143:606-616

Varanini Z, Pinton R (2001) Direct versus indirect effects of soil humic substances on plant growth and nutrition. In: Pinton R, Varanini Z, Nannipieri P (eds) The rhizosphere. Marcel Dekker, Basel, pp 141-158

Verma VC, Singh SK, Prakash S (2011) Bio-control and plant growth promotion potential of siderophore producing endophytic Streptomyces from Azadirachta indica A. Juss J Basic Microbiol 51:550-556. doi:10.1002/jobm.201000155

Vera J, Castro J, Contreras R, González A, Moenne A (2012) Oligo-carrageenans induce a long-term and broad-range protection against pathogens in tobacco plants (var. Xanthi). Physiol Mol Plant Pathol 79:31-39

Verkleij FN (1992) Seaweed extracts in agriculture and horticulture: a review. Biol Agric Hortic 8:309-324

Vernieri P, Borghesi E, Ferrante A, Magnani G (2005) Application of biostimulants in floating system for improving rocket quality. J Food Agric Environ 3:86-88

Vespermann A, Kai M, Piechulla B (2007) Rhizobacterial volatiles affect the growth of fungi and Arabidopsis thaliana. Appl Environ Microbiol 73:5639-5641

Vessey JK (2003) Plant growth promoting rhizobacteria as biofertilizers. Plant Soil 255:571-586. doi:10.1023/ a: 1026037216893

Vivas A, Marulanda A, Ruiz-Lozano J, Barea J, Azcón R (2003) Influence of a Bacillus sp. on physiological activities of two arbuscular mycorrhizal fungi and on plant responses to PEGinduced drought stress. Mycorrhiza 13:249-256. doi:10. 1007/s00572-003-0223-Z

Vranova V, Rejsek K, Skene KR, Formanck P (2011) Non-protein amino acids: plant, soil and acosystem interactions. Plant Soil 342:31-48 
Walch-Liu P, Ivanov II, Filleur S et al (2006a) Nitrogen regulation of root branching. Ann Bot 97:875-881

Walch-Liu P, Liu L-H, Remans T, Tester M, Forde BG (2006b) Evidence that ${ }_{\mathrm{L}}$-Glutamate can act as an exogenous signal to modulate root growth and branching in Arabidopsis thaliana. Plant Cell Physiol 47:1045-1057

Wally OSD, Critchley AT, Hiltz D et al (2013) Regulations of phytohormone biosynthesis and accumulation in Arabidopsis following treatment with commercial extract from the marine macroalga Ascophyllum nodosum. J Plant Regul 32:324-339

Watson R, Fowden L (1975) The uptake of phenylalanine and tyrosine by seedling root tips. Phytochemistry 14:1181-1186

Wilson MK, Abergel RJ, Raymond KN, Arceneaux JEL, Byers BR (2006) Siderophores of Bacillus anthracis, Bacillus cereus, and Bacillus thuringiensis. Biochem Biophys Res Commun 348:320-325

Wu C-C, Singh P, Chen M-C, Zimmerli L (2010) L-Glutamine inhibits beta-aminobutyric acid-induced stress resistance and priming in Arabidopsis. J Exp Bot 61:995-1002

Wu SC, Caob ZH, Lib ZG, Cheunga KC, Wonga MH (2005) Effects of biofertilizer containing $\mathrm{N}$-fixer, $\mathrm{P}$ and $\mathrm{K}$ solubilizers and AM fungi on maize growth: a greenhouse trial. Geoderma 125:155-166

Xudan X (1986) The effect of foliar application of fulvic acid on water use, nutrient uptake and yield in wheat. Aust J Agric Res 37:343-350

Yazdani M, Pirdashti H (2011) Efficiency of co -inoculation phosphate solubilizer microorganisms ( $\mathrm{psm}$ ) and plant growth promoting rhizobacteria (PGPR) on micronutrients uptake in corn (Zea mays L.). Int Res J Appl Basic Sci 2:28-34

Yildrim E (2007) Foliar and soil fertilization of humic acid affect productivity and quality of tomato. Acta Agric Scand 57: 182-186, Sect. B

Zahir ZA, Arshad M, Frankenberger WT Jr (2003) Plant growth promoting rhizobacteria: applications and perspectives in agriculture. Adv Agron 81:97-168
Zaidi S, Usmani S, Singh BR, Musarrat J (2006) Significance of Bacillus subtilis strain SJ-101 as a bioinoculant for concurrent plant growth promotion and nickel accumulation in Brassica juncea. Chemosphere 64:991-997. doi:10.1016/j. chemosphere.2005.12.057

Zancani M, Bertolini A, Petrussa E, Krajňájivá J, Piccolo A (2011) Fulvic acid affects proliferation and maturation phases in Abies cephalonica embryogenic cells. J Plant Physiol 168: 1226-1233

Zandonadi DB, Canellas LP, Façanha R (2007) Indolacetic and humic acids induce lateral root development through a concerted plasmalema and tonoplast $\mathrm{H}^{+}$pumps activation. Planta 225:1583-1595

Zhang Q, Zhang J, Shen J, Silva A, Dennis DA (2006) A simple 96-well microplate method for estimation of total polyphenol content in seaweeds. J Appl Phycol 18:445-450

Zhang X, Ervin EH (2004) Cytokinin-containing seaweed and humic acid extracts associated with creeping bentgrass leaf cytokinins and drought resistance. Crop Sci 44:1737-1745

Zhang X, Ervin EH (2008) Impact of seaweed extract-based cytokinins and zeatin riboside on creeping bentgrass heat tolerance. Crop Sci 48:364-370

Zhang X, Wang K, Ervin EH (2010) Optimizing dosages of seaweed extract-based cytokinins and zeatin bioside for improving creeping bentgrass heat tolerance. Crop Sci 50:316-320

Zhuang X, Chen J, Shim H, Bai Z (2007) New advances in plant growth-promoting rhizobacteria for bioremediation. Enviorn Int 33:406-413. doi:10.1016/j.envint.2006.12.005

Zimmerli L, Hou B-H, Tsai C-H et al (2008) The xenobiotic betaaminobutyric acid anhances Arabidopsis thermotolerance. Plant J 53:144-156

Zodape ST, Gupta A, Bhandari SC et al (2011) Foliar application of seaweed sap as biostimulant for enhancement of yield and quality of tomato (Lycopersicon esculentum Mill.). J Sci Ind Res 70:215-219

Zodape ST, Kawarkhe VJ, Patolia JS, Warade AD (2008) Effect of liquid seaweed fertilizer on yield and quality of okra (Abelmoschus esculentus L.). J Sci Ind Res 67:1115-1117 